\title{
Ensemble Sensitivity Analysis for Mesoscale Forecasts of Dryline Convection Initiation $\mathscr{0}$
}

\author{
Aaron J. Hill, Christopher C. Weiss, And Brian C. Ancell \\ Atmospheric Science Group, Department of Geosciences, Texas Tech University, Lubbock, Texas
}

(Manuscript received 29 September 2015, in final form 24 May 2016)

\begin{abstract}
Two cases of dryline convection initiation (CI) over north Texas have been simulated (3 April 2012 and 15 May 2013) from a 50-member WRF-DART ensemble adjustment Kalman filter (EAKF) ensemble. In this study, ensemble sensitivity analysis (ESA) is applied to a convective forecast metric, maximum composite reflectivity (referred to as the response function), as a simple proxy for $\mathrm{CI}$ to analyze dynamic mesoscale sensitivities at the surface and aloft. Analysis reveals positional and magnitude sensitivities related to the strength and placement of important dynamic features. Convection initiation is sensitive to the evolving temperature and dewpoint fields upstream of the forecast response region in the near-CI time frame $(0-12 \mathrm{~h})$, prior to initiation. The sensitivity to thermodynamics is also manifest in the magnitude of dewpoint gradients along the dryline that triggers the convection. ESA additionally highlights the importance of antecedent precipitation and cold pool generation that modifies the pre-CI environment. Aloft, sensitivity of CI to a weak short-wave trough and capping inversion-level temperature is coherent, consistent, and traceable through the entire forecast period. Notwithstanding the (often) non-Gaussian distribution of ensemble member forecasts of convection, which violate the underpinnings of ESA theory, ESA is demonstrated to sufficiently identify regions that influence dryline CI. These results indicate an application of ESA for severe storm forecasting at operational centers and forecast offices as well as other mesoscale forecasting applications.
\end{abstract}

\section{Introduction}

Drylines in the central and southern plains of the United States are localized mesoscale forcing mechanisms for discrete deep convection (Carlson and Ludlam 1968; Schaefer 1986; Ziegler and Rasmussen 1998). The along-boundary vertical mesoscale circulations (e.g., Atkins et al. 1998; Ziegler and Rasmussen 1998; Weiss and Bluestein 2002; Weiss et al. 2006) may aid in parcel lifting within and near the dryline convergence zone, a primary ingredient for storm initiation (Doswell and Bosart 2001). Although the importance of drylines in severe storm development is fairly well understood, forecasting their position, intensity, and the severe

Supplemental information related to this paper is available at the Journals Online website: http://dx.doi.org/10.1175/ MWR-D-15-0338.s1.

Corresponding author address: Aaron J. Hill, Department of Geosciences, Texas Tech University, Box 41053, Lubbock, TX 79409.

E-mail: aaron.hill@ttu.edu thunderstorms forced by the boundary remains difficult. Errors, for example, in the precise location of the parent synoptic cyclone, the distribution of boundary layer moisture (e.g., Holt et al. 2006), the intensity of capping inversions, and the strength of vertical mixing processes are critical components that contribute to the lack of predictability of drylines and subsequent severe storm development. Over the last few decades, computing capabilities have drastically improved, allowing researchers to produce higher-resolution simulations that more accurately capture dryline structure, movement, and the initiation of deep convection.

Deterministic convection allowing models on the order of 1-km horizontal grid spacing have proven valuable in improving the forecasts of deep moist convection, as outlined by Kain et al. (2013). As grid spacing is reduced, smaller-scale phenomena (e.g., convection physics) are explicitly computed and high-resolution simulations have been shown to provide more accurate forecasts than their coarser counterparts that may parameterize convective processes (Clark et al. 2009). Even with convection-allowing resolutions, deterministic models remain imperfect (Coffer et al. 2013; Bryan 
2005; Clark et al. 2015; Schumacher 2015) and further understanding of forecast variability can be gained through the use of ensemble prediction systems. Ensemble modeling and forecasting have provided the means to estimate forecast uncertainty by computing a larger suite of deterministic model solutions, valuable to understanding the predictability limitations of dryline convection initiation (CI). Additionally, ensemble assimilation systems, such as the ensemble Kalman filter (EnKF; Evensen 1994), are capable of spreading observational information through covariances between model state variables, enhancing the analyses of model forecasts. The coupling of ensemble systems and highresolution models has the potential to greatly improve the predictability of dryline $\mathrm{CI}$, including the location, timing, and severity of severe thunderstorms.

A plethora of predictability studies have focused on the advantages of performing sensitivity tests to determine how forecast features evolve within numerical models to influence chosen responses. Sensitivity studies using various methods (e.g., singular vectors, Kalman filter, adjoint, explicit perturbing) have highlighted the impact of model-state perturbations on forecast error (e.g., Liu and Kalnay 2008; Kalnay et al. 2012; Kang and Xu 2012; Ancell 2013), ensemble spread (e.g., Hamill and Snyder 2002; Qin and Mu 2011), and dynamics (e.g., Martin and Xue 2006; Melhauser and Zhang 2012). Adjoint sensitivity, for example, maps the gradient of a chosen forecast metric with respect to the forecast state back to an initial time to obtain a measure of sensitivity of the forecast metric to arbitrary perturbations in the initial conditions (LeDimet and Talagrand 1986). Adjoint sensitivity reveals dynamic links between perturbations in the initial state and the chosen forecast aspect. However, adjoint sensitivity is a time consuming and computationally expensive effort that involves the adjoint model. Adjoint sensitivity also requires that the nonlinear model be differentiable and it becomes less accurate for larger perturbations and longer forecast windows due to its inherent linearity assumption. Even with these limitations, a variety of adjoint studies have shown utility in producing identifiable features that may be associated with the propagation and growth of forecast error (e.g., Errico and Vukićević 1992; Rabier et al. 1996; Errico 1997; Errico et al. 2003).

Other studies have evaluated sensitivity of forecasts to initial condition perturbations by varying initial condition inputs for ensemble members (Melhauser and Zhang 2012) and explicitly perturbing state variables (Martin and Xue 2006). Melhauser and Zhang (2012) showed that forecast sensitivity of convective mode related to a bow echo was primarily attributable to smallscale differences in the initial conditions related to moist processes. By filtering good and poor ensemble members, and running subsequent forecasts with varying initial conditions weighted by the good and poor members, they discovered a limited predictability in forecasting convection because of such initial condition sensitivities. Previously, Zhang et al. (2003) illustrated that moist processes (e.g., through convective and microphysical parameterizations) create a limitation to mesoscale predictability, enhancing the Melhauser and Zhang (2012) findings. Furthermore, Martin and Xue (2006) utilized a large ensemble to carry out perturbation experiments on water vapor mixing ratio, soil moisture, and meridional wind near the surface to forecasts of precipitation. They showed strong dynamic links of precipitation development along a dryline to the employed perturbations with strong nonlinear precipitation responses.

Here the authors explore a technique that requires minimal computational expense and a capability to reveal dynamic features in the initial conditions that may impact CI timing forecasts. Ensemble-based sensitivity analysis (ESA; Ancell and Hakim 2007; Hakim and Torn 2008; Torn and Hakim 2008) develops linear relationships between a scalar forecast metric and initial conditions strictly through ensemble statistics. Compared to adjoint sensitivity, minimal computations are required once ensemble forecasts have been created. ESA has been extensively applied to synoptic-scale features related to extratropical cyclones (e.g., Ancell and Hakim 2007; Torn and Hakim 2008; Garcies and Homar 2009, 2010; Chang et al. 2013; McMurdie and Ancell 2014), extratropical transition (e.g., Torn and Hakim 2009), and tropical cyclones (e.g., Torn 2010; Ito and Wu 2013; Torn and Cook 2013; Xie et al. 2013; Torn 2014). The linear relationships between forecasts and initial conditions on the synoptic scale have been thoroughly investigated with ESA. On the mesoscale, the utility of ESA has been investigated, for example, for wind power forecasting (Zack et al. 2010a,b,c, 2011a,b) as well as more recently for convection-permitting forecasts in the southern plains (Bednarczyk and Ancell 2015) and in the Mesoscale Predictability Experiment (MPEX; Torn and Romine 2015; Weisman et al. 2015). Bednarczyk and Ancell (2015) were the first to illustrate the utility of ESA for normally distributed convection forecasts and highlighted forecast sensitivities of convective variables (e.g., spatially averaged reflectivity, vertical velocity, and precipitation) to the upstream synoptic flow pattern and low-level thermodynamic characteristics. MPEX utilized ESA for the targeting of dropsonde deployments upstream of mesoscale convective forecasts and discovered synopticscale sensitivities to potential vorticity anomalies for precipitation forecasts. 


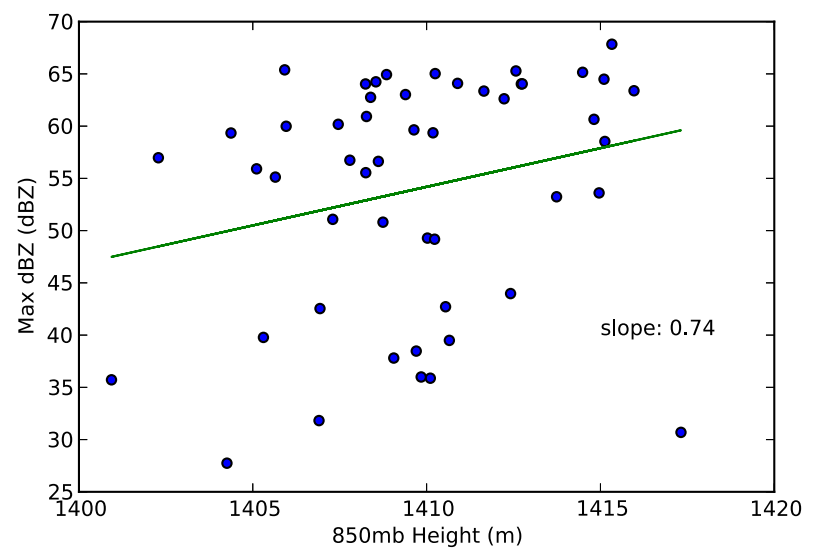

FIG. 1. Scatter (blue circles) of maximum reflectivity (dBZ) in a defined response region against $850-\mathrm{hPa}$ geopotential height (m) at a grid point and associated linear regression (green line). Calculated slope of the regression function represents the value of sensitivity at the grid point.

The purpose of this study is to determine whether ESA is useful when applied to a discontinuous, binary forecast metric-the initiation of convection. We propose that ESA applied to CI forecasts can effectively identify features influencing the timing of severe convection along drylines. Two case studies are presented here that consist of dryline-initiated convection in northcentral Texas with ESA applied to a forecast metric designated as a simple proxy to diagnose the initiation of deep moist convection. Previously, Bednarczyk and Ancell (2015) evaluated the sensitivity of convection after initiation, once the ensemble developed a normally distributed forecast metric among ensemble members. At that point ESA was able to reveal positional (e.g., east-west location of the parent $500-\mathrm{hPa}$ trough) or magnitude (e.g., moisture content of plumes feeding the convection) signals in the sensitivity field. The current study suggests that even a bimodal distribution of a forecast response may be appropriately assessed with linear-based ESA techniques to improve and understand mesoscale predictability of severe convection.

The paper is outlined as follows: a brief overview of ESA and the modeling system is presented in section 2; section 3 provides an overview of the two cases; sensitivity fields are evaluated for both case studies, at the surface and aloft, in section 4; and a summary and discussion are presented in section 5 .

\section{Methodology}

\section{a. Ensemble sensitivity}

A relationship between a chosen scalar forecast metric $R$ and the model forecast state $x_{t}$ at an earlier time $t$ is

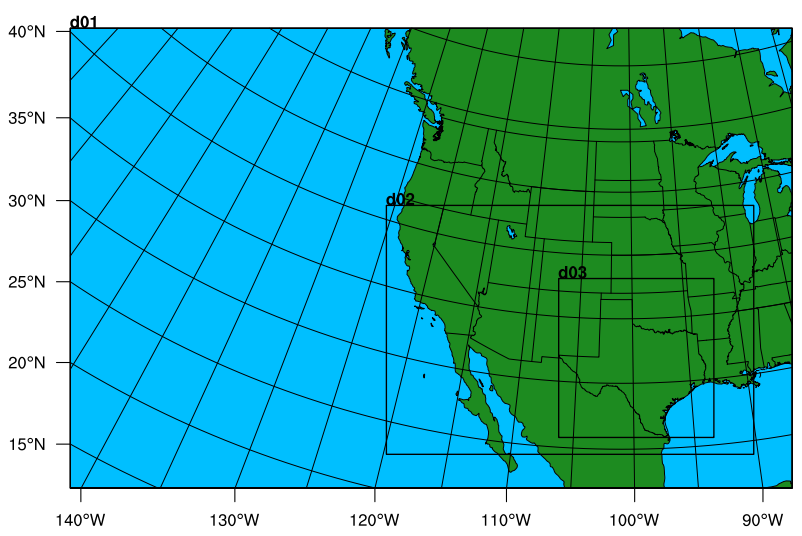

FIG. 2. WRF domain configuration with 36-, 12-, and 4-km grid spacing for d01, d02, and d03 domains, respectively. Modeled after the former Texas Tech University real-time ensemble system.

developed through a linear regression of ensemble forecast metric estimates to the earlier model state. This relationship is described by Ancell and Hakim (2007) as

$$
\frac{\partial R}{\partial x_{t}}=\frac{\operatorname{cov}\left(R, x_{t}\right)}{\operatorname{var}\left(x_{t}\right)}
$$

where cov and var denote the covariance and variance of the given variables, respectively. The sensitivity value $\partial R / \partial x_{t}$ is the slope of the linear regression between the ensemble estimates of $R$ and earlier-time model state (e.g., see Fig. 1). Readers are referred to Ancell and Hakim (2007) for the full derivation of ensemble sensitivity and its relationship to adjoint sensitivity.

Statistical significance is applied to the estimate of the sample distribution regression slope coefficient (i.e., sensitivity) with a $90 \%$ confidence interval (see Wilks 2011, section 7.2.5). In other words, there is $90 \%$ confidence that the true population sensitivity is contained within the sample distribution and the null hypothesis, that changes to the initial conditions will not affect the response metric, may be rejected with the same confidence interval. All sensitivity displayed hereafter meets this statistical significance threshold. This approach additionally mitigates sampling-error impacts that are introduced by estimating the sample variance and covariance from a relatively small ensemble compared to the degrees of freedom (Torn 2010).

Maximum composite reflectivity (MDBZ) computed in a region of $\mathrm{CI}$ (i.e., response region) is chosen as the forecast variable of interest. MDBZ is computed for the three-dimensional space within the response region. The forecast region was chosen based on the ensemble representation of CI in model reflectivity as well as observational information from archived WSR-88D data, including which storms produced the most severe 

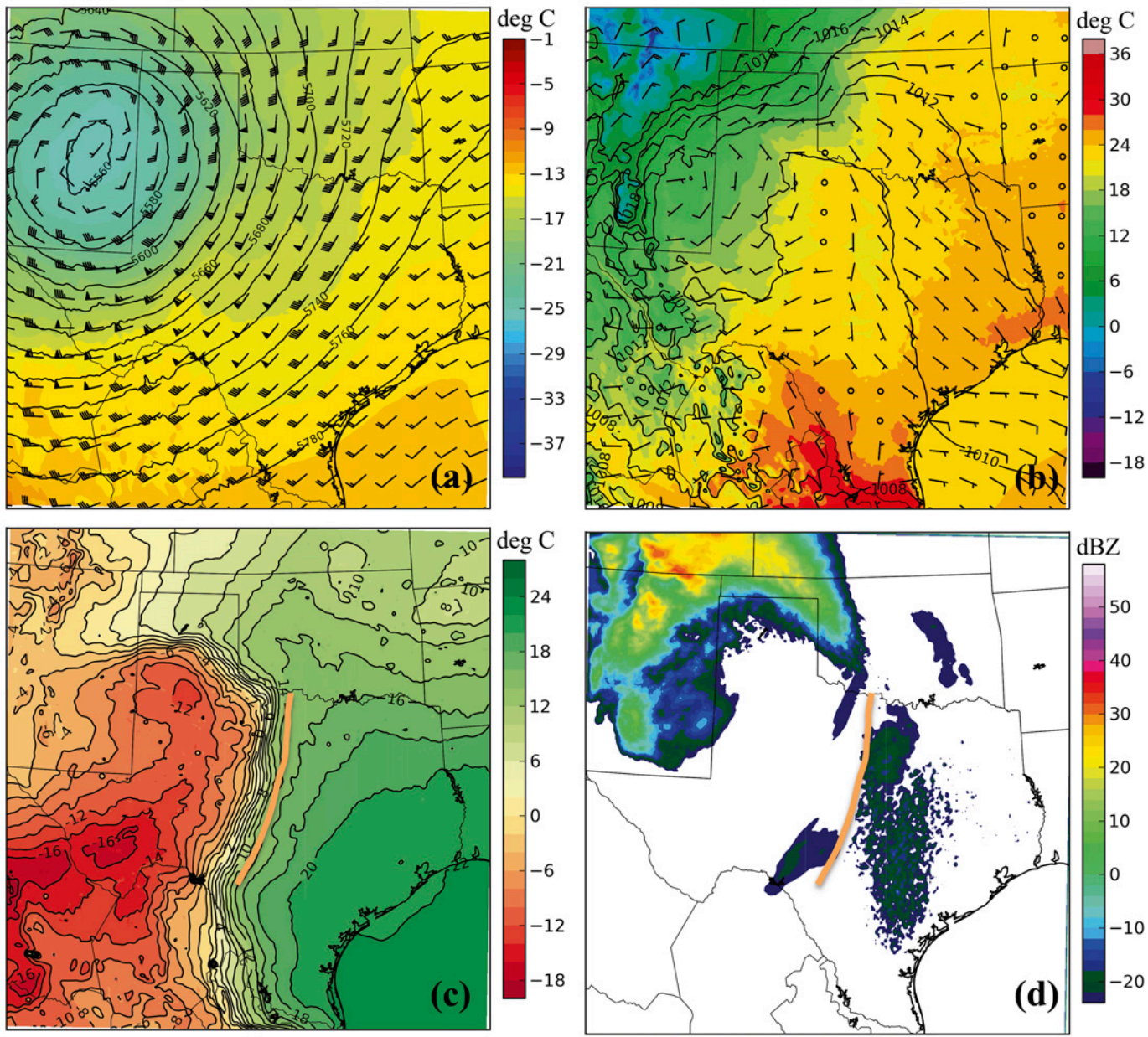

FIG. 3. (a) Ensemble mean 500-hPa geopotential height (m, contoured every $20 \mathrm{~m})$, temperature $\left({ }^{\circ} \mathrm{C}\right.$, shaded), and vector wind (kt, barbs). (b) Ensemble mean sea level pressure (hPa, contoured every $2 \mathrm{hPa}$ ), 2-m temperature $\left({ }^{\circ} \mathrm{C}\right.$, shaded), and $10-\mathrm{m}$ vector wind (kt, barbs). (c) Ensemble mean 2-m dewpoint temperature $\left({ }^{\circ} \mathrm{C}\right.$, shaded and contoured every $2^{\circ} \mathrm{C}$ ). (d) Ensemble mean composite reflectivity (dBZ, shaded). All fields are valid at forecast hour 19 for APR3 (1900 UTC 3 Apr 2012). The orange line in (c) and (d) represents the subjectively analyzed dryline placement discussed in the text.

weather. MDBZ represents an instantaneous measure of convective vigor, in contrast to Bednarczyk and Ancell (2015), who used spatially averaged forecast metrics that relate to convection (e.g., composite reflectivity, precipitation) in their analysis of convective sensitivity, which are more likely to be normally distributed. By using maximum values, the signal of convection initiation is not washed out from averaging and the nonlinear forecast evolution is more likely captured within the forecast metric resulting in a non-Gaussian response. In extreme cases as will be presented in this study, the resulting distribution may become bimodal.

With a bimodal forecast distribution, one objective approach to compare and evaluate sensitivity fields is to compute subset mean differences (SMDs); differencing the sets of convection initiating and noninitiating ensemble member forecast fields. Bednarczyk and Ancell (2015) demonstrate the utility of this differencing technique by using single ensemble members and discover that differences between individual members are consistent with the regression slope calculated across all members. This approach alleviates the computational cost of explicit perturbation approaches in evaluating sensitivity fields and it will be used in this study to validate sensitivities both at the surface and aloft. A threshold of $20 \mathrm{dBZ}$ is subjectively chosen as a cutoff value between members that are producing convection $(>20 \mathrm{dBZ})$ and those that do not $(<20 \mathrm{dBZ})$. This value was chosen based on the forecast distributions of each case, which will be discussed in the next section. Means of the separate distribution modes are then calculated, differenced, and compared against the sensitivity fields 

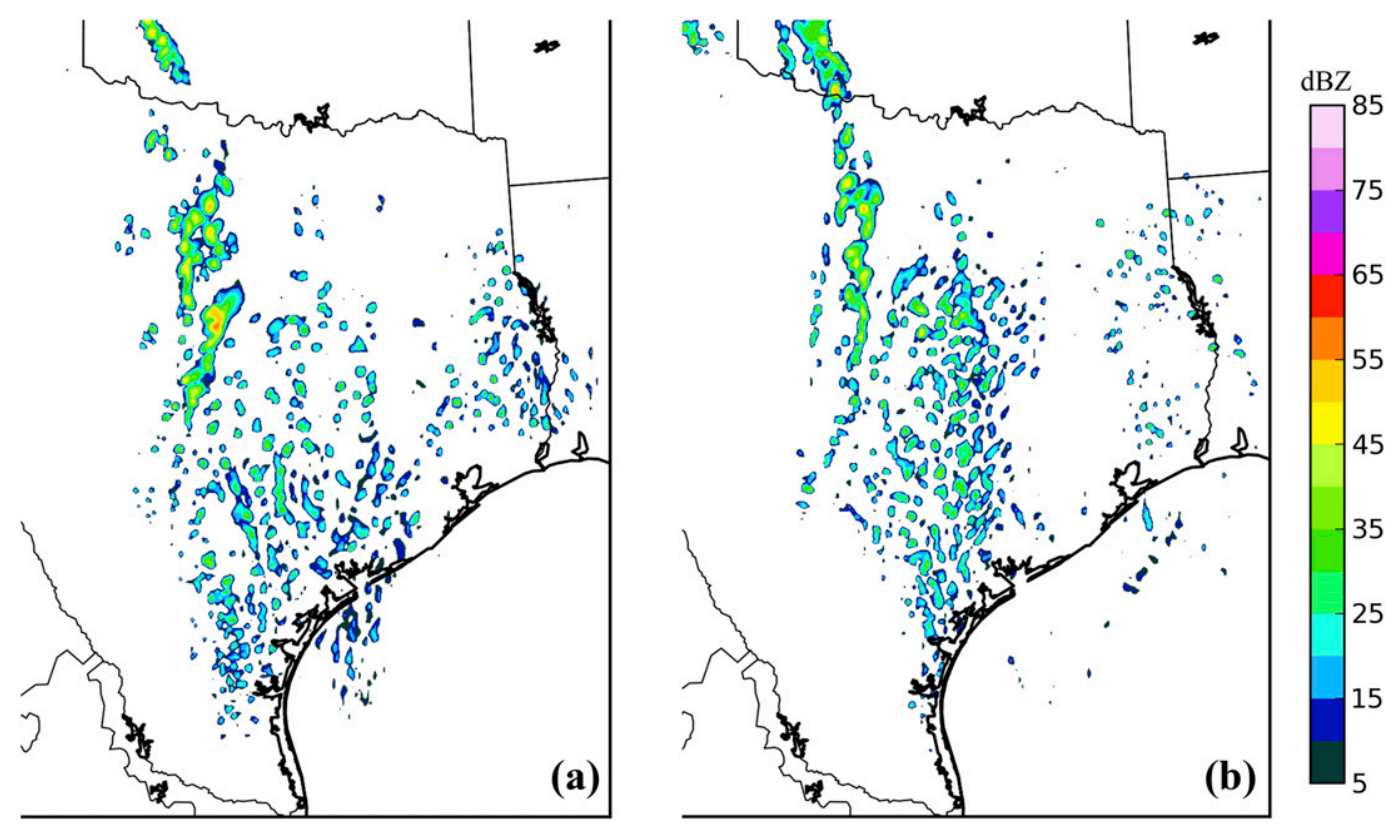

FIG. 4. Composite reflectivity (dBZ, shaded) of ensemble members (a) 23 and (b) 30 at forecast hour 19 for APR3.

to analyze how differences in the forecast evolution and resulting distribution are highlighted by the sensitivity.

\section{b. Model and assimilation configuration}

A 50-member ensemble is generated by perturbing boundary and initial conditions from the National
Centers for Environmental Prediction (NCEP) Global Forecast System (GFS) using the WRF three-dimensional variational data assimilation (Barker et al. 2004) and fixed covariance boundary perturbation technique (Torn et al. 2006). The initial conditions are interpolated to a domain with $36-\mathrm{km}$ horizontal grid spacing centered over the
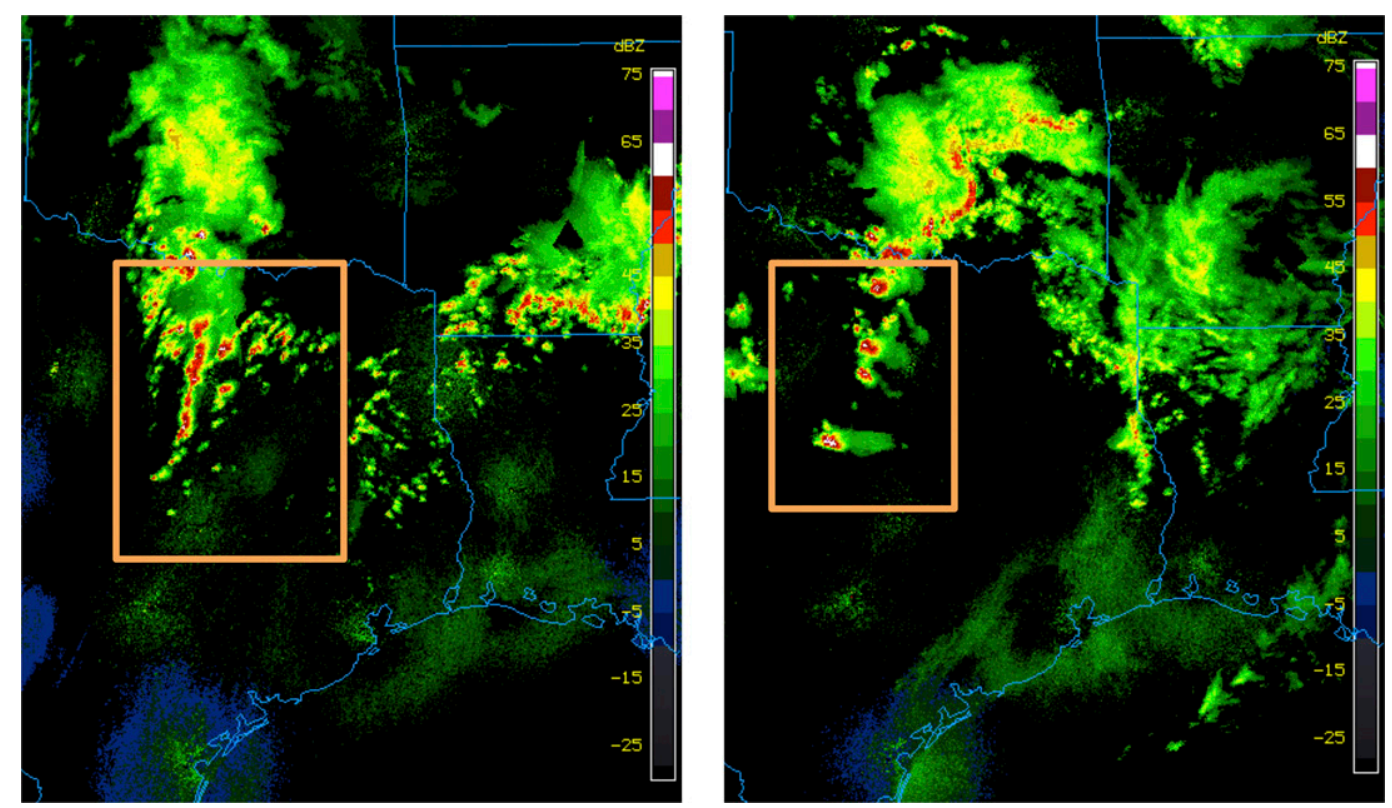

FIG. 5. 1-km radar reflectivity (dBZ) at (left) 1853 UTC 3 Apr 2012 and (right) 2359 UTC 15 May 2013 from the University Corporation for Atmospheric Research (UCAR) image archive of composite WSR-88D data. Orange boxes note areas of convection discussed in the text. 

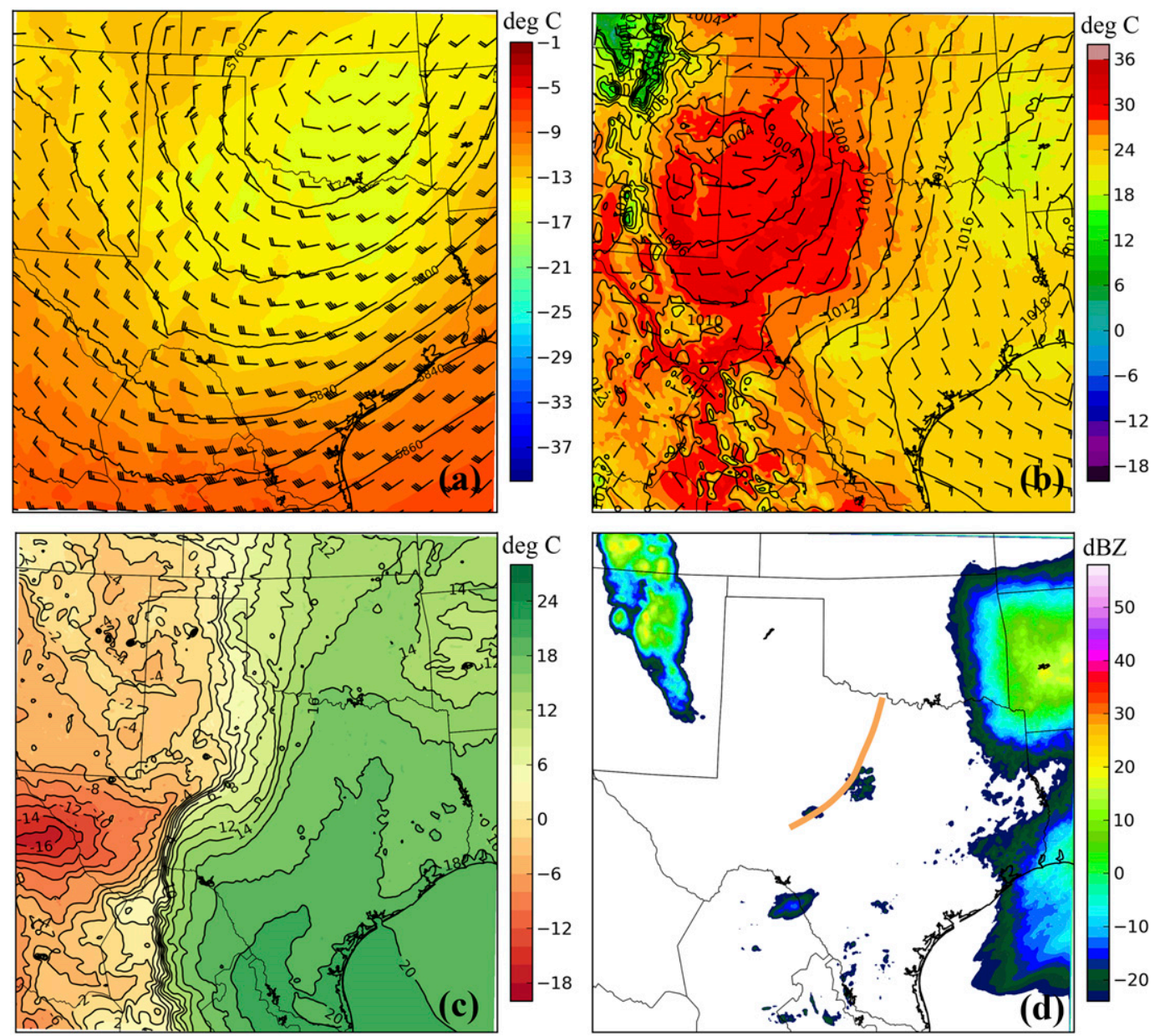

FIG. 6. As in Fig. 3, but at forecast hour 24 for MAY15 (0000 UTC 16 May 2013).

western United States. Two one-way nested domains with 12- and 4-km horizontal grid spacing reside over the West Coast and southern United States (Fig. 2). The ensemble is integrated forward in time with version 3.3.1 (Skamarock et al. 2008) of the Advanced Research version of the Weather Research and Forecasting (WRF-ARW) mesoscale model with 38 vertical model levels.

Data assimilation is completed using an ensemble adjustment Kalman filter (EAKF; Anderson 2001) within the Data Assimilation Research Testbed (DART; Anderson et al. 2009) utility. The outermost domain is run on a 6-hourly update cycle for $24 \mathrm{~h}$. Observations from the following platforms are assimilated on all domains: surface temperature, winds, moisture (i.e., specific and relative humidity), and pressure; Aircraft Communications Addressing and Reporting System (ACARS) temperature, winds, and moisture; radiosonde temperature, winds, and moisture; marine temperature, winds, moisture, and pressure; and satellite-derived winds obtained from the Meteorological Data Acquisition System (MADIS). Once this first day of cycling is completed, the inner-nested domains are initialized through the WRF Model one-way nest-down procedure and assimilation is completed on all three domains every $6 \mathrm{~h}$ for an additional $24 \mathrm{~h}$ with respective parent domains providing boundary and initial conditions for the nests. This 48-h spinup period is run to ensure flow-dependent relationships within the ensemble that were originally initialized with static climatological covariances. Only analyses and forecasts from the innermost 4-km domain will be evaluated in this study.

Because of underdispersion within the ensemble, a spatially and temporally adapting inflation algorithm (Anderson 2007, 2009) is utilized to promote more realistic spread. The need for inflation is based upon the principle that sampling error is high when the ensemble size is significantly smaller than the degrees of freedom. Additionally, to reduce spurious covariances during assimilation, covariance localization (Houtekamer and Mitchell 1998; Hamill et al. 2001) is employed to reduce the impact of observations at large distances from the 


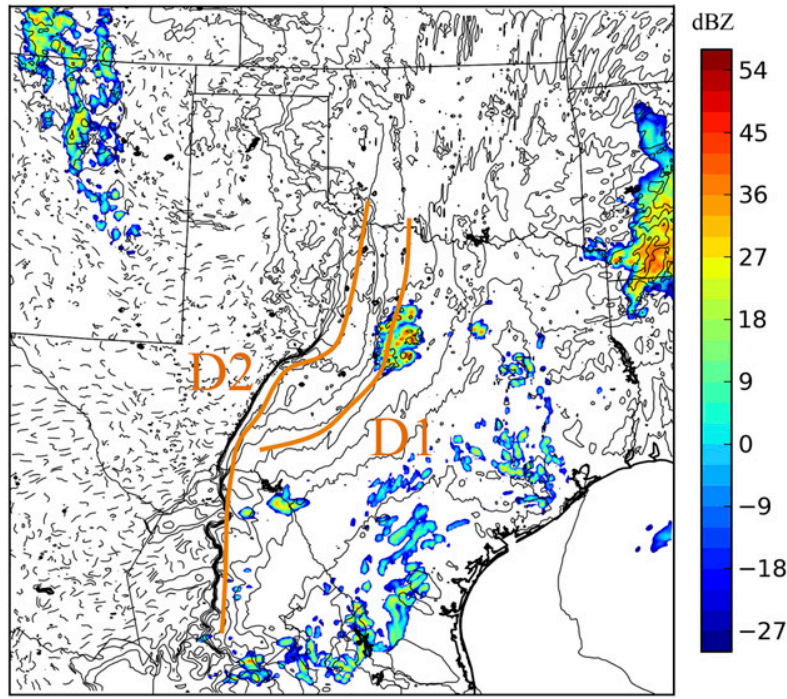

FIG. 7. Composite reflectivity ( $\mathrm{dB} Z$, shaded) and 2-m dewpoint temperature $\left({ }^{\circ} \mathrm{C}\right.$, positive values solid and negative values dashed) at forecast hour 24 from an individual ensemble member from MAY15. Orange lines indicate position of the primary (D1) and secondary (D2) drylines discussed in the text.

observation location. A Gaspari-Cohn localization function (Gaspari and Cohn 1999) is used at each observation location with horizontal half-widths of 600 and $300 \mathrm{~km}$, and vertical half-widths of 0.075 and $0.025 \mathrm{~km}$ for the outermost and nested domains, respectively, so that observations have no influence at distances of 2 times the half-width from the observation location and beyond. Furthermore, boundary conditions on the outermost domain are perturbed about GFS forecasts as outlined by Torn et al. (2006) to maintain spread.

All domains utilize the Yonsei University (YSU) boundary layer (Hong et al. 2006), Noah land surface model (Chen and Dudhia 2001), Rapid Radiative Transfer Model longwave radiation (Mlawer et al. 1997), Dudhia shortwave radiation (Dudhia 1989), and Thompson microphysical (Thompson et al. 2004) parameterization schemes to model subgrid-scale phenomena. The 4-km domain provides enough resolution to explicitly simulate convective processes (Kain et al. 2013) with a sufficient number of ensemble members (Schwartz et al. 2014), alleviating the use of a cumulus parameterization scheme. On the coarser domains, the Kain-Fritsch cumulus parameterization (Kain 2004) is employed.

\section{Case descriptions}

\section{a. April 2012}

Ensemble forecasts are generated for two cases of CI along drylines in north-central Texas. The first case is

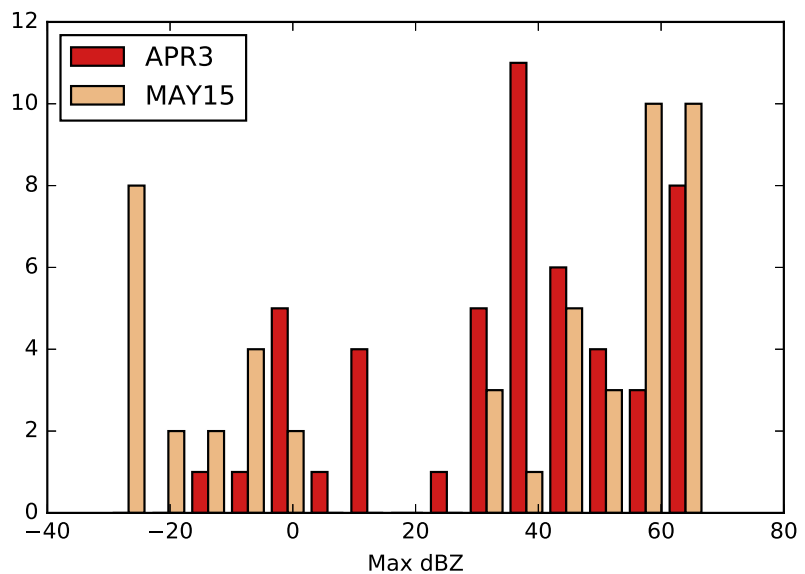

FIG. 8. Histogram distribution of the forecast metric (MDBZ) for APR3 (red) and MAY15 (tan) at the initiation time that the forecast metric is defined (1900 UTC and 0000 UTC for APR3 and MAY15, respectively).

3 April 2012 (hereafter APR3) with CI observed at 1800 UTC as determined from archived WSR-88D data (not shown). Forecasts from EAKF-generated analyses are initialized at 0000 UTC 3 April 2012 (after the 48-h spinup period described above) and run $24 \mathrm{~h}$. Ensemble mean fields at forecast hour 19 show a midtropospheric trough at $500 \mathrm{hPa}$ progressing eastward through New Mexico and into west Texas as the convective event was unfolding, with strong southwesterly wind speeds greater than $50 \mathrm{kt}\left(1 \mathrm{kt}=0.5144 \mathrm{~m} \mathrm{~s}^{-1}\right)$ downstream of the trough axis (Fig. 3a). At the surface, cyclonic flow is evident over the domain associated with an inverted trough (Fig. 3b). Weak southerly to southeasterly surface flow attendant to north-central Texas, coupled with the aforementioned trough and jet aloft, provided sufficient deep-layer shear to promote discrete supercells within the modest warm sector. A dryline and strong confluence axis are positioned in central Texas at this time (Fig. 3c) collocated with the developed convection within the ensemble (Fig. 3d).

Multicellular clustered convection was present along the dryline (e.g., Figs. 4a,b) initially in ensemble member simulations. Observations indicated a similar depiction along with supercells developing out ahead of the dryline (Fig. 5a, area in orange rectangle). The single cell development was observed in model-simulated reflectivity in a subset of ensemble members, an example of two in Fig. 4, and is the focus of our sensitivity analysis as these storms produced the most severe weather. It should be noted that the timing of CI in the majority of ensemble members that produced convection in the response region lagged observations of $\mathrm{CI}$ by $1 \mathrm{~h}$; a few members produced convection at later times, which will be discussed in a following section. Additionally, while 


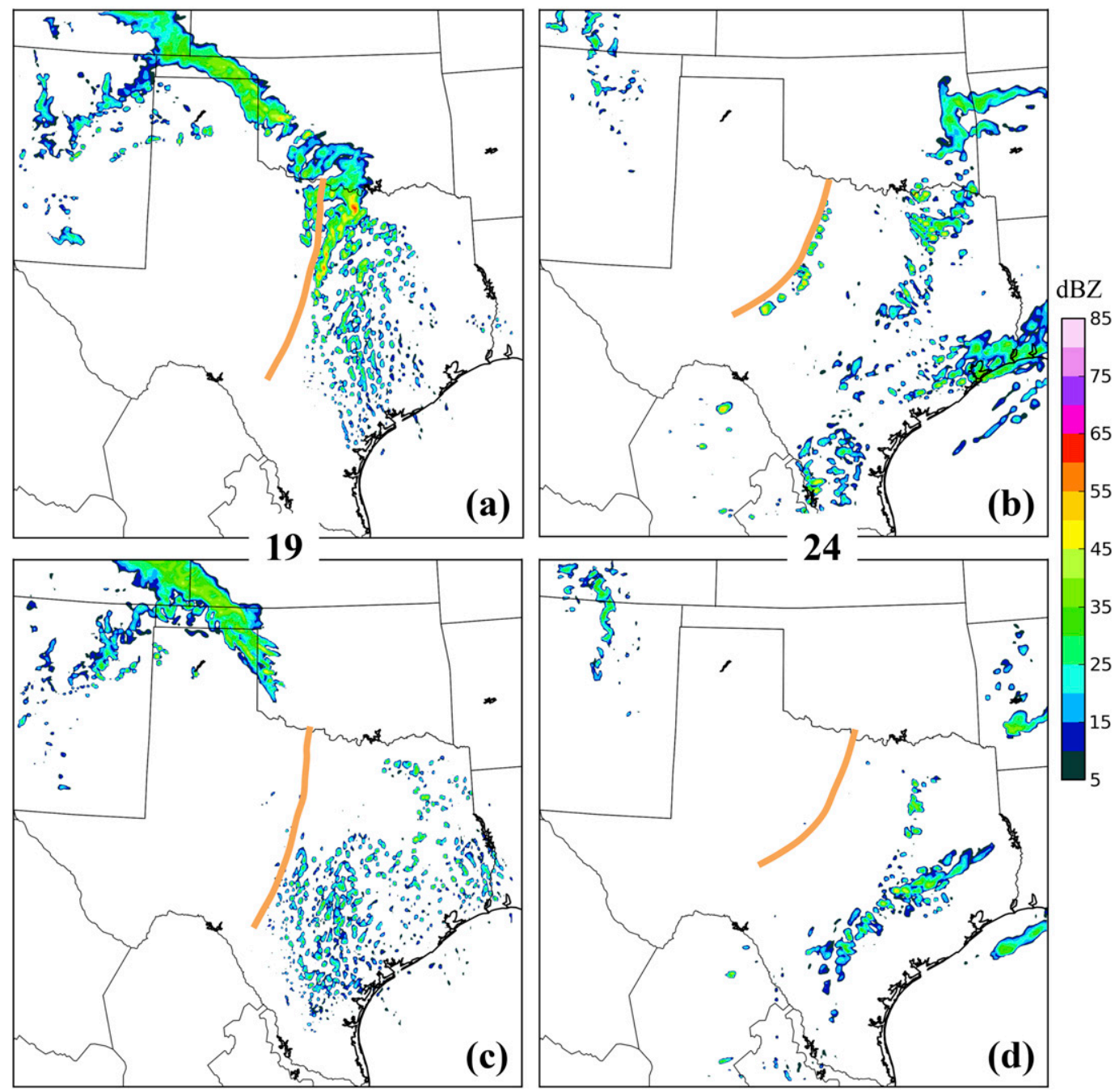

FIG. 9. Composite reflectivity (dBZ, shaded) of ensemble members (a) 48 and (c) 31 at forecast hour 19 for APR3 and members (b) 13 and (d) 3 at forecast hour 24 for MAY15. Orange lines indicate the analyzed dryline locations for both cases discussed in the text.

the position of convection in north-central Texas was reasonably represented in the model, the forecast missed convection that had been present and intensified in central and southern Oklahoma (not shown). The Oklahoma convection provided a secondary forcing from a southward-propagating outflow boundary, aiding in storm-scale organization and initiation within northcentral Texas. While differences do exist between the model fields and observations, these differences do not detract from the sensitivity results presented as the observed event is captured within the ensemble distribution scope. Thus, the investigation of sensitivity still reveals how the forecast is sensitive to reoccurring and important forcing mechanisms (i.e., dryline) in the southern plains. The differences, however, are important to note since there will be no sensitivity signals to unforecasted forcing mechanisms, a limitation of ESA with poor initial conditions and forecasts.

\section{b. May 2013}

The second case presented in this study occurred 15 May 2013 (hereafter MAY15) in central Texas with convection initiating at 2300 UTC, as indicated by archived radar data (not shown). The ensemble forecasts were initialized 0000 UTC 15 May 2013 and again integrated forward $24 \mathrm{~h}$ after a 48 -h spinup period. Aloft, a positively tilted trough at $500 \mathrm{hPa}$ is positioned over Oklahoma and extending southwestward into southern Texas at forecast hour 24 (Fig. 6a). The strongest winds aloft were east of the trough axis at $\sim 40 \mathrm{kt}$ from the westsouthwest. The coldest temperatures at $500 \mathrm{hPa}$ existed over the Oklahoma-Texas border, extending into 
T2
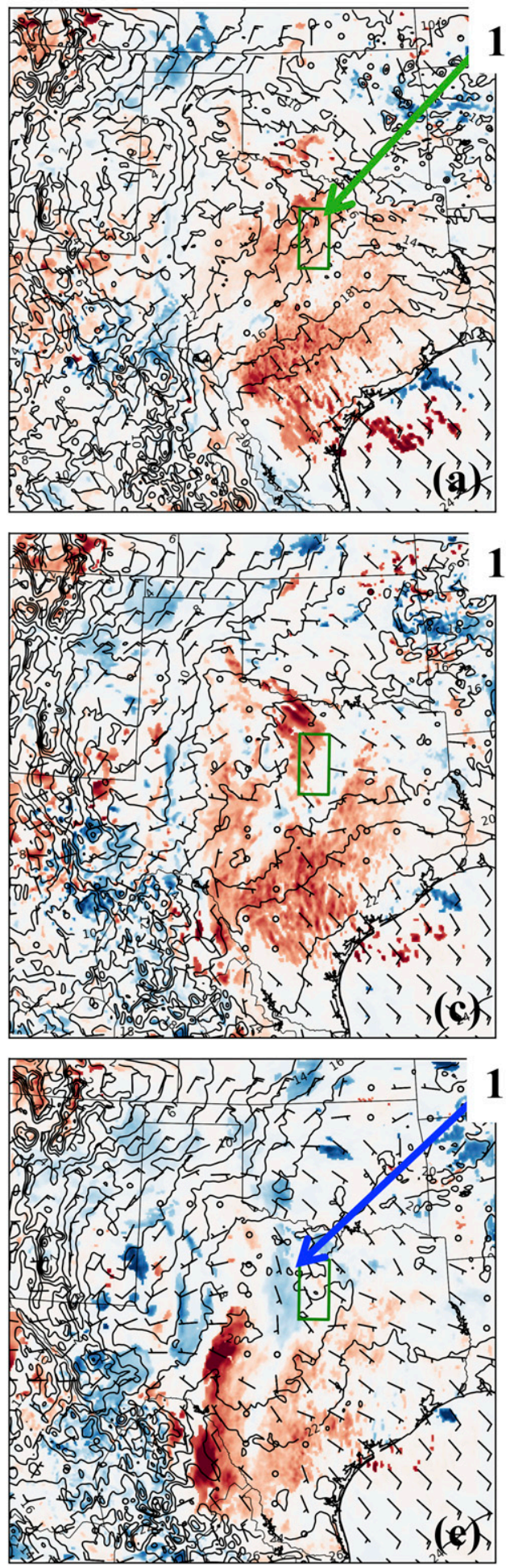

TD2
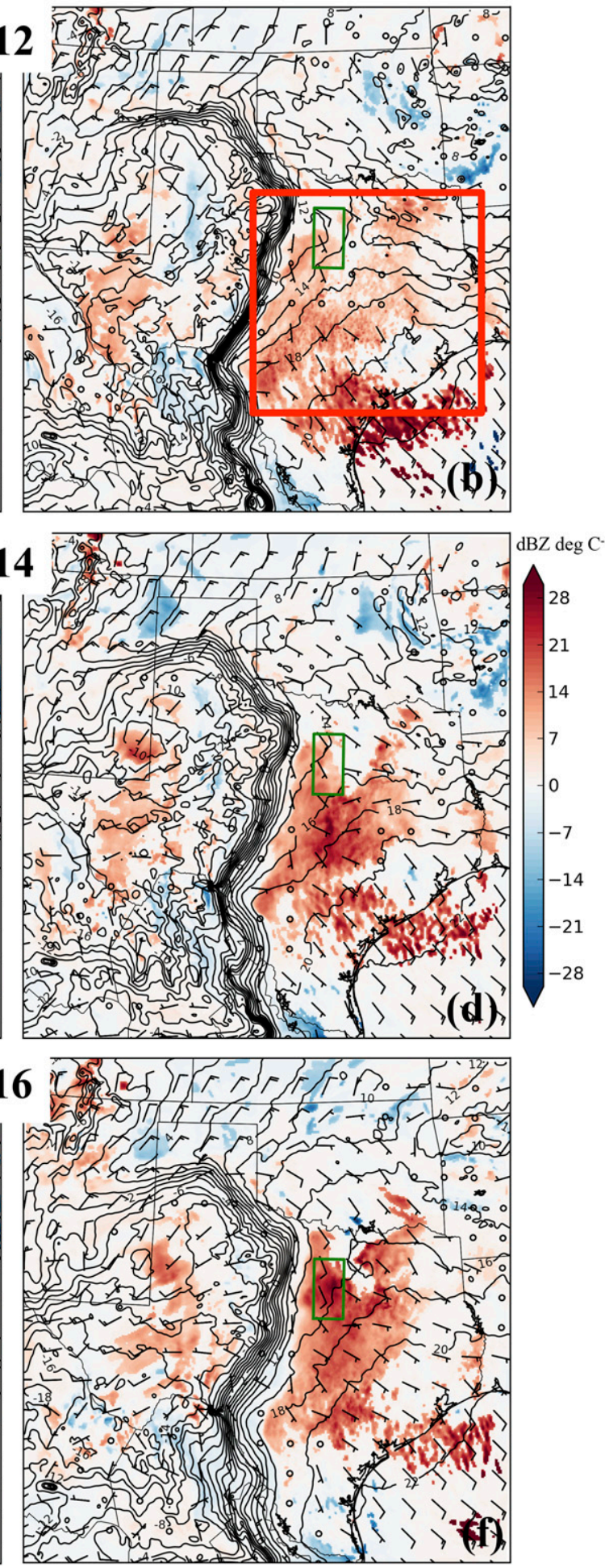

FIG. 10. Sensitivity of MDBZ at forecast hour 19 to $2-\mathrm{m}$ temperature ( $\mathrm{dBZ}{ }^{\circ} \mathrm{C}^{-1}$, shaded) at hours (a) 12 , (c) 14 , and (e) 16 and sensitivity to 2 -m dewpoint temperature $\left(\mathrm{dBZ}{ }^{\circ} \mathrm{C}^{-1}\right.$, shaded) at forecast hours (b) 12 , (d) 14 , and (f) 16 for APR3. The ensemble means of the respective background fields are contoured every $2^{\circ} \mathrm{C}$. Green arrow points to the location of the response region (green rectangle). Red rectangle and blue arrow highlight sensitive regions discussed in the text. 
T2
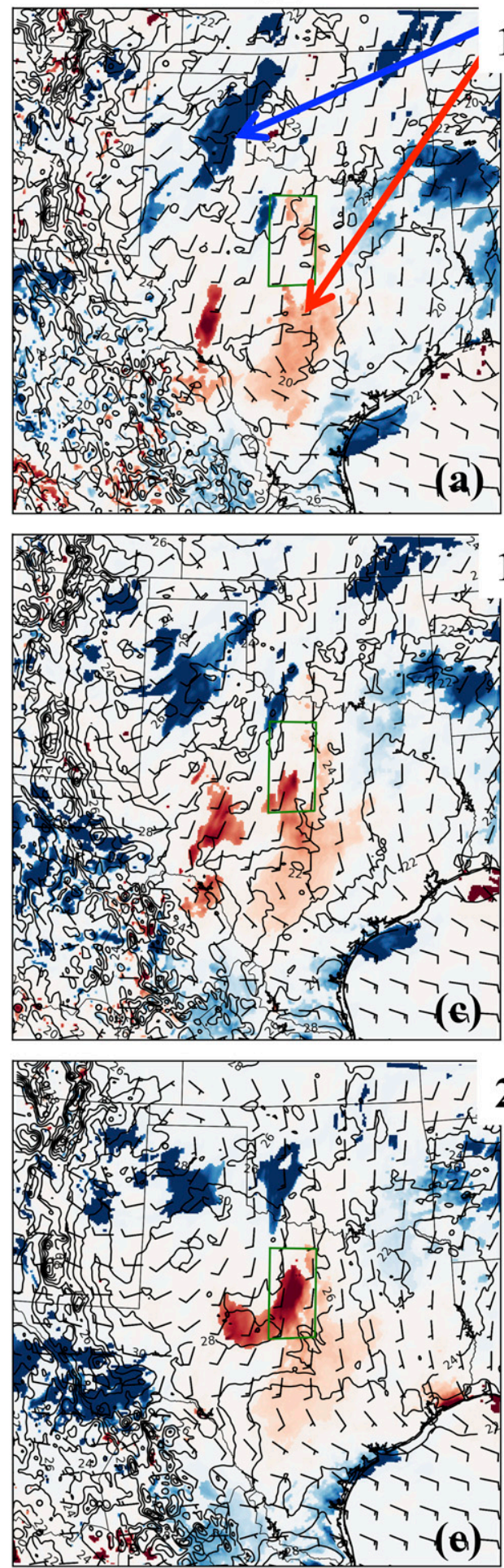

TD2
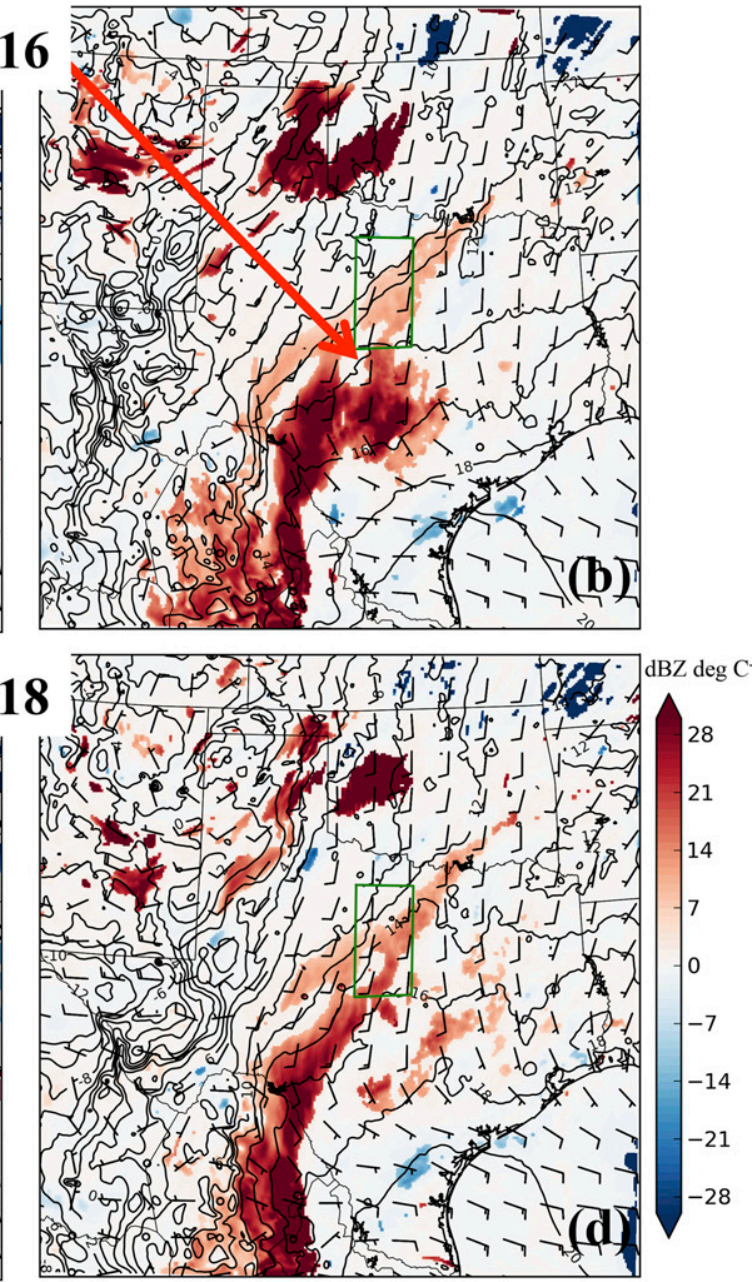

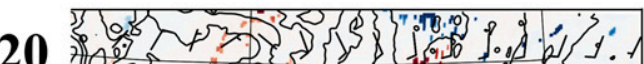

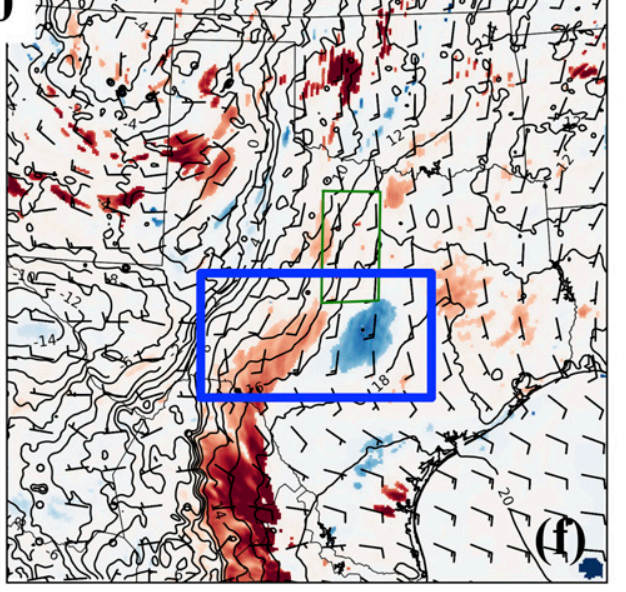

FIG. 11. As in Fig. 10, but for sensitivities of MDBZ at forecast hour 24 to initial conditions at forecast hours (a),(b) 16; (c),(d) 18; and (e),(f) 20 in MAY15. Red and blue arrows and blue rectangles highlight sensitive regions discussed in the text. 

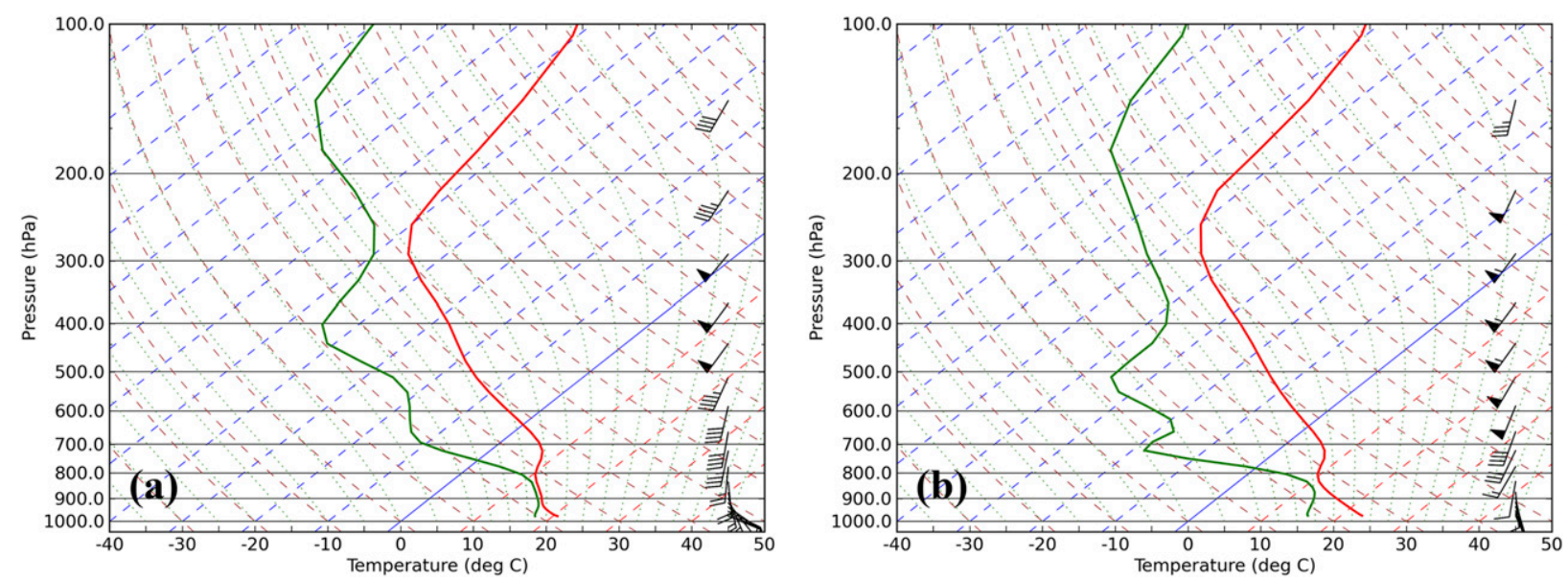

FIG. 12. Model forecast skew $T-\log p$ diagrams from (a) APR3 at forecast hour 18 and (b) MAY15 at forecast hour 23. Each profile is an area average over the response region. The red line denotes temperature $\left({ }^{\circ} \mathrm{C}\right)$ and the green line denotes dewpoint temperature $\left({ }^{\circ} \mathrm{C}\right)$.

central Texas. Strong surface heating is evident over west Texas (Fig. 6b) south of a developing surface cyclone in the region. Strong southerly winds were present in central Texas with a long fetch extending toward the Gulf of Mexico, providing ample near-surface moisture. Considerable spread exists in the forecast of dryline position within the ensemble, thus the mean field of 2-m dewpoint exhibits weaker gradients compared to individual members (Figs. $6 \mathrm{c}$ and 7). In general, a primary dryline is in central Texas (D1 in Fig. 7) with the southern extent bending back toward the west. A secondary dryline exists in far western Texas extending southward into Mexico and the higher terrain of southwest Texas (D2 in Fig. 7). Focus will be placed on the primary dryline hereafter.

Similar to APR3, the ensemble forecast of CI lagged observation-indicated initiation by $1 \mathrm{~h}$. Although a robust CI signal is not evident in the ensemble mean composite reflectivity (Fig. 6d), a considerable number of ensemble members had initiated with a generally correct location of convection by forecast hour 24 (e.g., Fig. 5b) in central Texas. However, the ensemble failed again to initialize convection that existed for the latter half of the forecast period in northern Texas and southern Oklahoma. In this case, however, no additional boundaries were present to influence the developing convection in central Texas. Furthermore, no members developed convection along the secondary dryline in west Texas, which was not an observed signal (Fig. 5b).

\section{c. Response metric distributions}

The distributions of MDBZ generalize the nonGaussian and bimodal nature of the $\mathrm{CI}$ forecast for each case. When evaluating the MDBZ forecast of all ensemble members, it is clear that both cases exhibit a
non-Gaussian, bimodal forecast distribution of convection (Fig. 8) with a clear distribution separation at $20 \mathrm{~dB} Z$ at their respective prescribed CI times of 19 and $24 \mathrm{~h}$, respectively for APR3 and MAY15.

In APR3, a subset of ensemble members had developed robust convection at forecast hour 19 in the response region (one member example in Fig. 9a), but another, smaller subset had not (one member example in Fig. 9c). Within the group that had not developed convection in the response region, a handful of members produced convection that was displaced westward. An investigation into the evolution of these "nonconvecting" labeled members at forecast hour 20 revealed that, while some members began to produce MDBZ greater than $20 \mathrm{dBZ}$, most convective cells were anchored along the dryline, continuously producing new updrafts, indicating a poor environment for sustaining and intensifying storms. This would suggest similar convectivefailure mechanisms of discrete supercells propagating off the dryline for members that may have produced weak cells along the dryline to the west and members that did not produce any convection within the central Texas region. Therefore, the grouping of these nonconvecting members into the small subset is appropriate.

Similarly, MAY15 has a two-mode distribution with a majority of members producing discrete supercells in central Texas (one member example in Fig. 9b) and a smaller subset producing weak or no simulated reflectivity (one member example in Fig. 9d) at forecast hour 24. Examination of the noninitiating members at forecast hour 25 shows one additional member that lagged significant $\mathrm{CI}$ along the dryline with a few other members producing isolated, small cells in the response region. It is important to understand how ESA can be utilized to identify features and environmental influences 

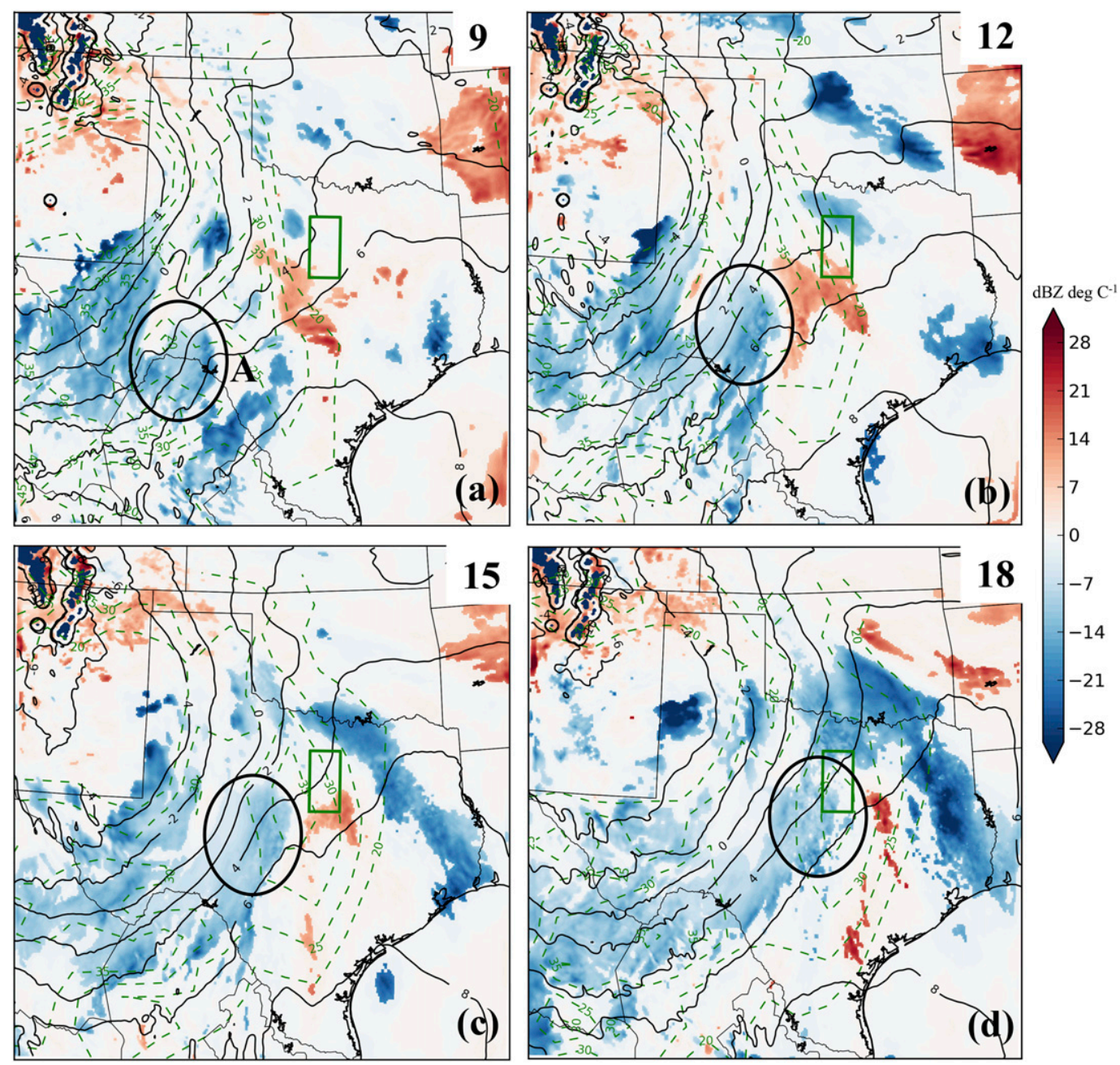

FIG. 13. Sensitivity of MDBZ at forecast hour 19 to $700-\mathrm{hPa}$ temperature $\left(\mathrm{dBZ}{ }^{\circ} \mathrm{C}^{-1}\right.$, shaded) at forecast hours (a) 9 , (b) 12 , (c) 15, and (d) 18 for APR3. Ensemble mean 700-hPa temperature and wind speed are contoured every $2^{\circ} \mathrm{C}$ (solid black) and $5 \mathrm{kt}$ (dashed green), respectively. The black circle labeled "A" is described and referenced in the text.

between these two ensemble subsets that lead to differences in CI timing, even when those differences are small.

\section{Results}

ESA has been applied to near-surface and midtropospheric variables to assess the sensitivity of CI forecasts to select thermodynamic and model pressure fields. These sensitivity fields are then compared to differences between mean fields of convecting and nonconvecting ensemble subsets from the respective response-distribution modes to highlight the dynamic signal present in the sensitivity analysis.

\section{a. Ensemble sensitivity analysis}

Ensemble sensitivity highlights dynamic features in the initial conditions or earlier forecast times that are relevant to the predictability of the forecast variable of interest. The forecast of MDBZ within the response region at forecast hour 19 in the APR3 simulation (Fig. 3d) is sensitive to near-surface thermodynamic characteristics upstream of the response region (green rectangle in Fig. 10), east of the dryline over central and southern Texas (red rectangle, Fig. 10b), beginning 7 hours prior to model CI. The forecast is positively sensitive to 2-m temperature (Fig. 10, left column) and 2-m dewpoint temperature (Fig. 10, right column) indicating that an increase in moisture and warming of the advected air mass would produce a higher maximum simulated reflectivity in the green box at hour 19 . Additionally, a narrow region of significant negative sensitivity to $2-\mathrm{m}$ temperature is evident west of the response region at forecast hour 16 (blue arrow, Fig. 10e). This signal is a result of convection-producing 

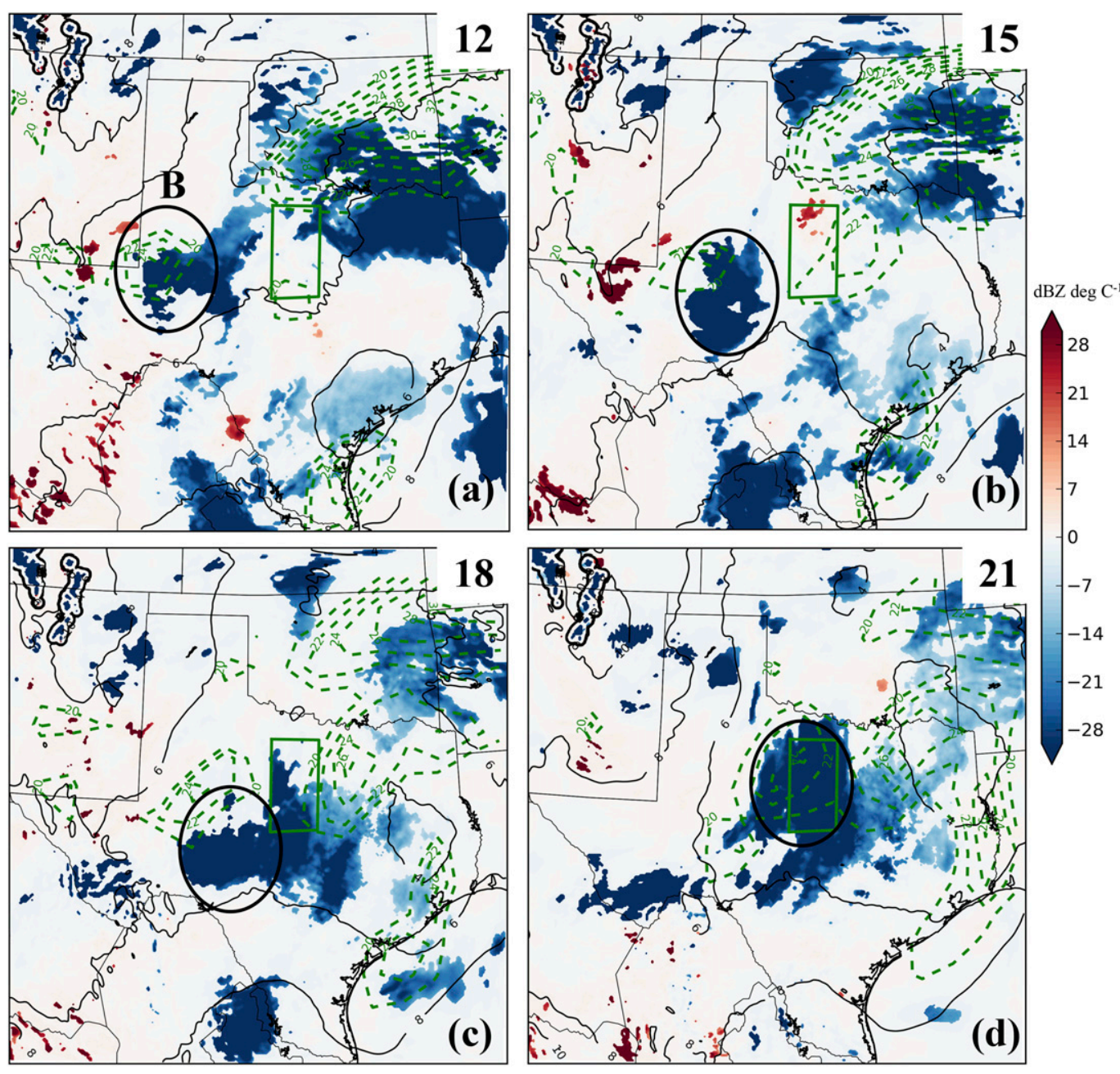

FIG. 14. As in Fig. 13, but for sensitivities of MDBZ at forecast hour 24 in MAY15 to initial conditions at forecast hours (a) 12, (b) 15, (c) 18, and (d) 21. Ensemble mean 700-hPa temperature and wind speed are contoured every $2^{\circ} \mathrm{C}$ (solid black) and $2 \mathrm{kt}$ (dashed green), respectively. The black circle labeled " $\mathrm{B}$ " is described and referenced in the text.

members developing weak simulated reflectivity in this region at earlier forecast lead times, producing a slightly cooler surface temperature (not shown). While the weak model-simulated reflectivity may not play a direct role in subsequent convection development, the sensitivity formulation captures the trend that members producing more robust convection a few hours later also have weak convection at earlier forecast times.

Similarly, the forecast of MDBZ at forecast hour 24 for MAY15 is positively sensitive in a broad region to upstream low-level temperature and dewpoint (red arrows, Fig. 11) at least 8 hours prior to CI. Positive sensitivity to 2-m temperature develops to the south of the response region at forecast hour 16 (Fig. 11a) and intensifies over the next 4 hours. Negative sensitivity to temperature within the Texas Panhandle (blue arrow,
Fig. 11a) is also shown to be statistically significant, although coherency between successive model times is weaker. It is unclear how this area may directly impact the reflectivity response, which is tied to the dryline. Explicit perturbation experiments may provide a clearer understanding of the dynamic relevance of the negative sensitivity, which is beyond the scope of this study. Robust positive sensitivity to 2-m dewpoint (Fig. 11, right column) is also present over southern Texas along and east of the developing dryline (blue rectangle, Fig. 11f). Higher near-surface moisture content east of the developing moisture gradient would be consistent with stronger horizontal confluence, and thus increased vertical lift. Furthermore, frontogenetical, thermally direct secondary circulations (e.g., Ziegler and Rasmussen 1998; Weiss and Bluestein 2002; Weiss et al. 

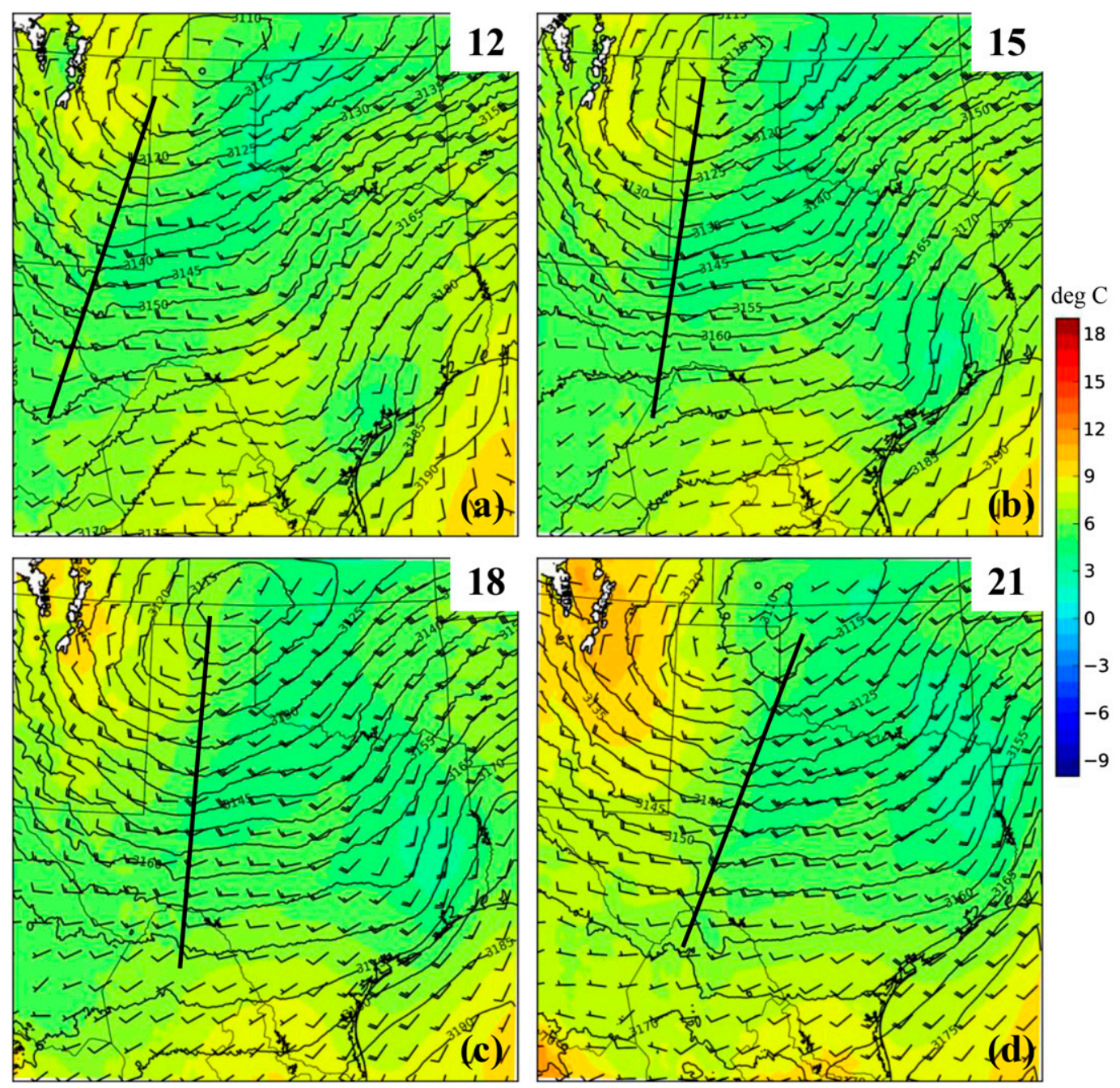

FIG. 15. Ensemble mean 700-hPa geopotential height (m, contoured every $5 \mathrm{~m})$, temperature $\left({ }^{\circ} \mathrm{C}\right.$, shaded), and wind speeds (kt, barbs) at forecast hours (a) 12, (b) 15, (c) 18, and (d) 21 for MAY15. The black line denotes the position of an analyzed short-wave trough.

2006) can develop in response to the tightening moisture gradient, which further drives gradient intensification and potential for vertical mixing processes to initiate convection.

At forecast hour 20, clear negative 2-m dewpoint sensitivity develops south of the response region and appears tied to the swath of adjacent positive sensitivity along the dryline (blue rectangle, Fig. 11f). Previous studies have shown that localized areas with a coupledsensitivity dipole are associated with positional sensitivities to boundary or synoptic system placement (Bednarczyk and Ancell 2015). In this case, however, there is no local maximum in dewpoint sensitivity attendant to the localized minimum, the latter of which was well out in front of the mean moisture gradient and developed only a few hours prior to CI. The authors speculate the sensitivity is related to antecedent cold pool generation, discussed further in the next section. Moreover, sensitivities to the near-surface thermodynamic characteristics develop temporal and spatial coherency within a 12-h time window before CI in both cases (see the animations in the online supplemental material). This coherency develops as a result of the dynamic link between the forecast and influential mesoscale kinematic and thermodynamic regions, which is revealed by SMDs discussed further in the next section.

Another major component to CI forecasting is the strength of midlevel capping inversions and their eventual deterioration through the forcing of upward vertical velocity and/or a sufficient amount of boundary layer heating to promote initiation. Averaged forecast soundings from the response region just prior to $\mathrm{CI}$ in 


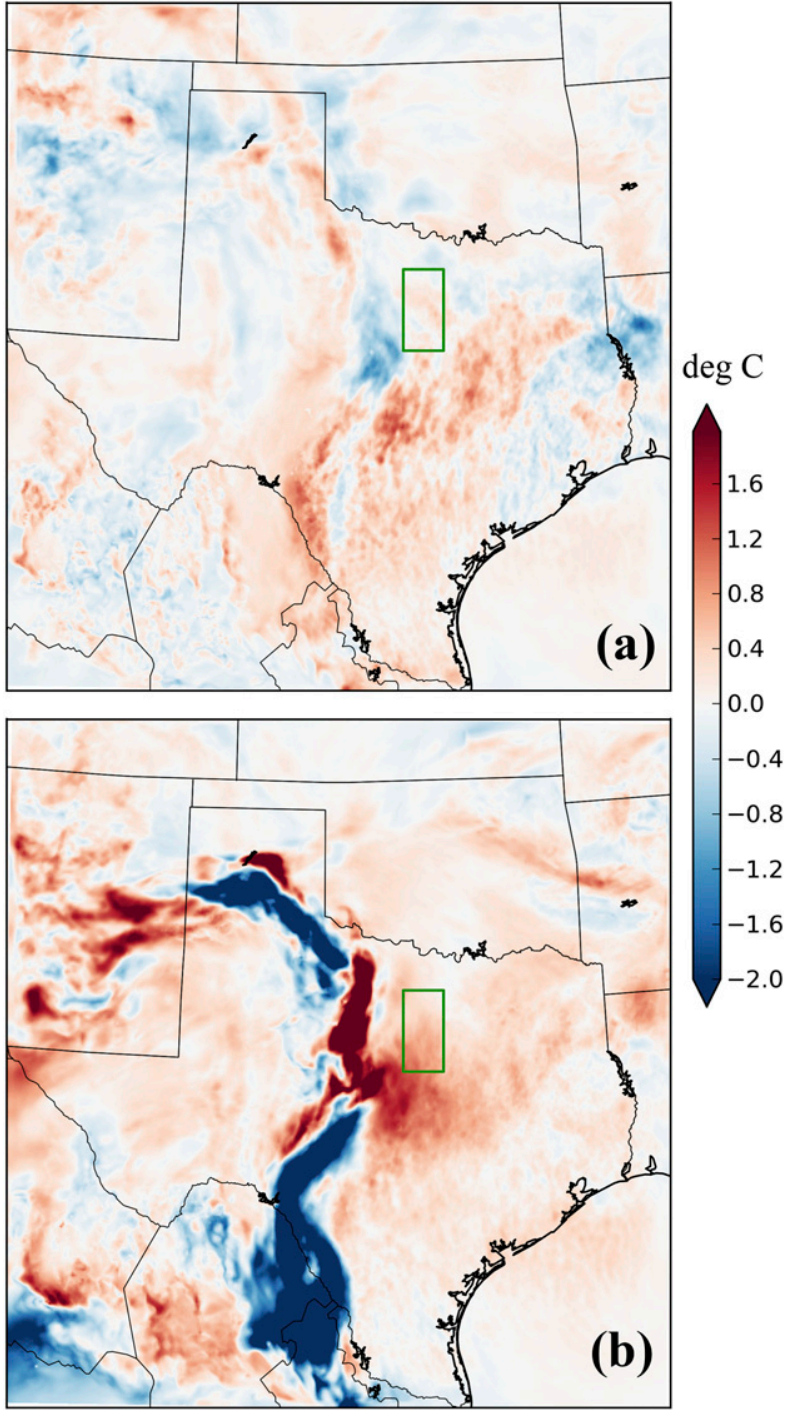

FIG. 16. Differences in (a) 2-m temperature $\left({ }^{\circ} \mathrm{C}\right.$, shaded) and (b) 2-m dewpoint temperature $\left({ }^{\circ} \mathrm{C}\right.$, shaded) at forecast hour 16 in APR3 between the convecting and nonconvecting ensemble subsets.

each case show an inversion located between 800 and $700 \mathrm{hPa}$ (Fig. 12). In APR3, an area of sensitivity to 700-hPa temperatures emanates from southwest Texas at forecast hour 9 and moves toward the response region by the time of CI (Fig. 13), presumably inhibiting potential convective development. There would be a positive response in MDBZ if temperatures were lowered in this region (labeled $\mathrm{A}$ in Fig. 13), corresponding to a weakening inversion. A noticeable thermal ridge (solid contours) is present with this highlighted area, which may be a reason for the presence of the negative sensitivity signal. A weaker thermal ridge (short-wave ridge) in this region would correspond to a positive response in

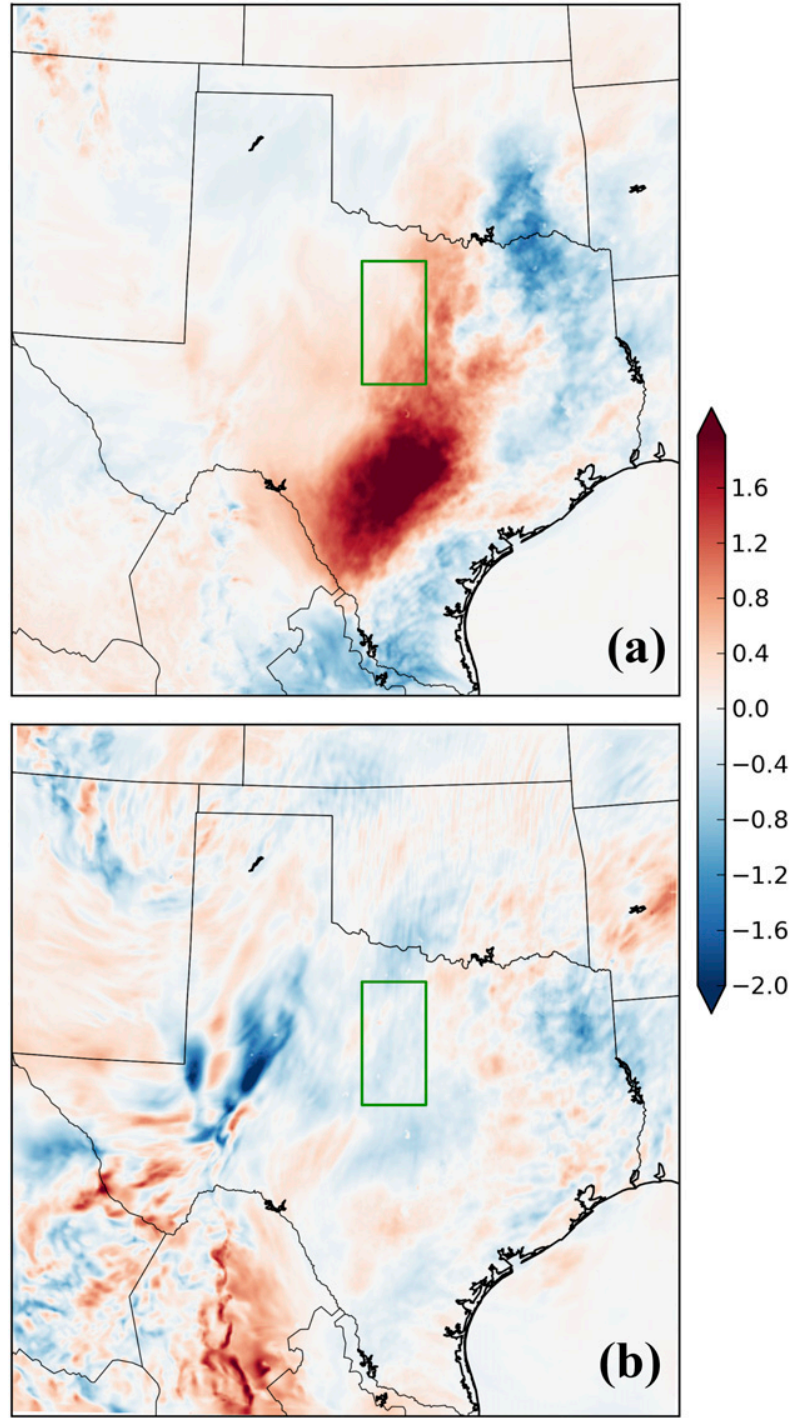

FIG. 17. As in Fig. 16, but at forecast hour 20 for MAY15.

MDBZ and the potential for more ensemble members to simulate storms.

In addition, the forecast of MDBZ in MAY15 has a negative sensitivity to $700-\mathrm{hPa}$ temperatures in a localized mesoscale region that moves eastward from west Texas (Fig. 14). The sensitivity signal present at $700 \mathrm{hPa}$ (labeled B in Fig. 14), collocated or west of a small region of greater than 20-kt winds, may be ultimately tied to forcing mechanisms helping to initiate convection. A weak 700-hPa short-wave trough moves with the sensitivity signal through the same temporal window (black line, Fig. 15). A short-wave trough would be associated with stronger winds and cooler air, thus this feature is consistent with the sensitivity signal and localized maximum in wind speeds. Therefore, ESA is valuable in identifying localized, dynamic, and influential areas on 

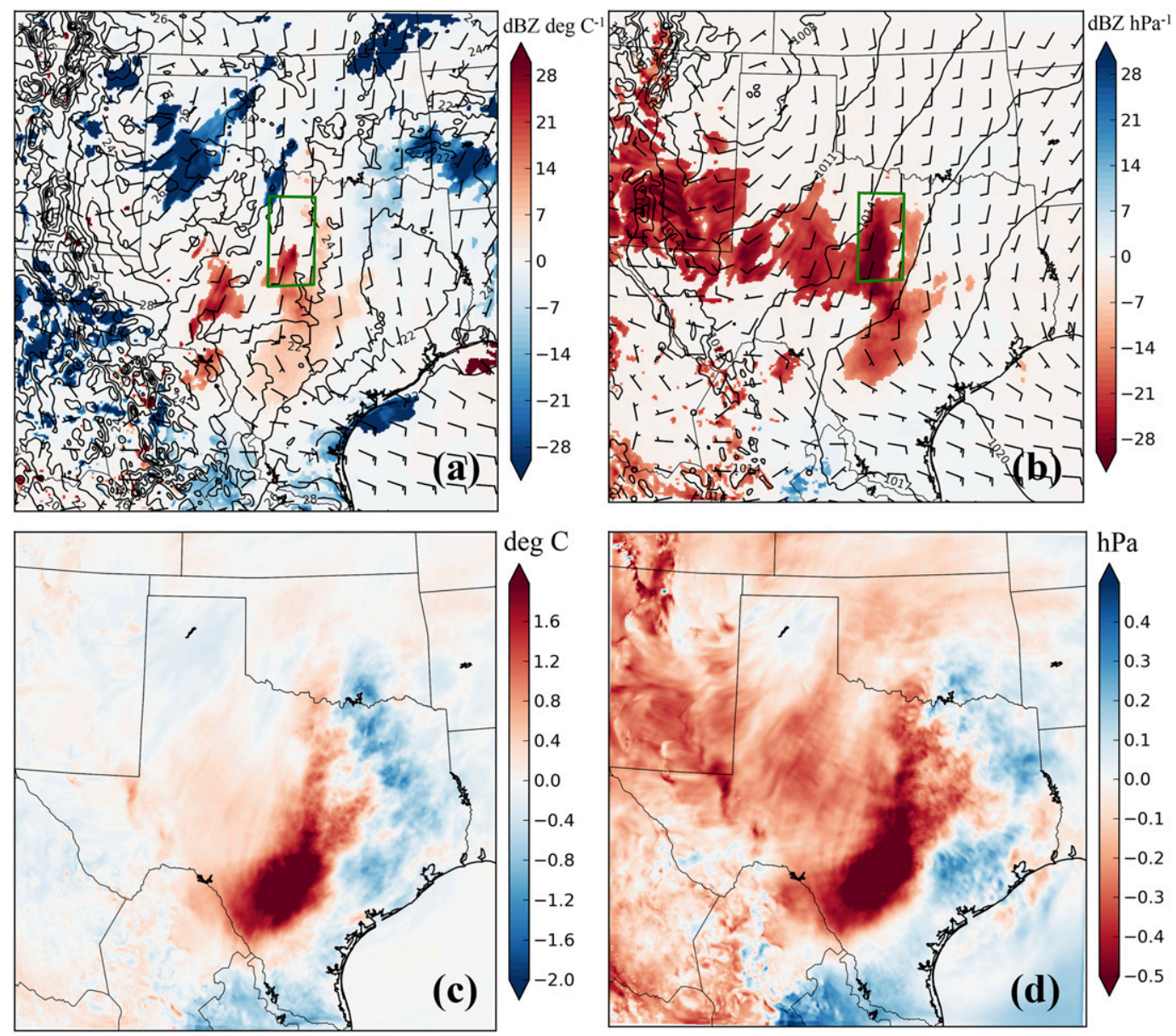

FIG. 18. Sensitivity of MDBZ at forecast hour 24 to (a) 2-m temperature ( $\mathrm{dBZ}{ }^{\circ} \mathrm{C}^{-1}$, shaded) and (b) sea level pressure $\left(\mathrm{dBZ} \mathrm{hPa}{ }^{-1}\right.$, shaded) at forecast hour 18 for MAY15. Ensemble mean fields are contoured every $2^{\circ} \mathrm{C}$ and $3 \mathrm{hPa}$, respectively. Differences of (c) 2-m temperature $\left({ }^{\circ} \mathrm{C}\right.$, shaded) and (d) sea level pressure (hPa, shaded) between the convecting and nonconvecting ensemble subsets at forecast hour 18 .

the CI forecast, even when the CI forecast metric is distributed nonnormally. The sensitivity feature is also coherent from early forecast times through the end of the forecast period where it resides over the response region. Sensitivity of CI to the presence of a capping inversion and upper-level forcing mechanisms is well understood and ESA has sufficiently highlighted these relationships.

\section{b. Subset differences}

A better dynamical understanding of the sensitivity fields may be gleaned from differencing subsets of ensemble members that are producing convection and those that are not. In APR3, areas of significant positive and negative sensitivity to 2-m temperature at hour 16 overlap regions where the subset members disagree the most (cf. Figs. 10e and 16a). Similar correlations exist between sensitivities of MDBZ to 2-m dewpoint and the subset mean differences of dewpoint $\left(\mathrm{SMD}_{\mathrm{TD} 2}\right.$; cf. Figs. 10f and 16b). Subsets differ considerably east of the dryline in central Texas and west of the dryline toward the New Mexico border, collocated with areas of positive sensitivity. Meaningful SMDs also occur along the dryline in central Texas with negative and positive dewpoint differences exceeding $2^{\circ} \mathrm{C}$.

Similar statements can be made for the MAY15 simulation, where areas of ensemble sensitivity discussed previously are well correlated to positions of considerable differences between convecting and nonconvecting subset surface thermodynamic fields. Large $\mathrm{SMD}_{\mathrm{T} 2}$ in central Texas is coincident with statistically significant sensitivity to $2-\mathrm{m}$ temperature (cf. Figs. $17 \mathrm{a}$ and 11c) seen at forecast hour 20. It is important to note that the largest differences between members are not always strongly correlated with areas of largest statistically significant sensitivity, as manifested from the statistical formulation of sensitivity, whereby the variance of the 


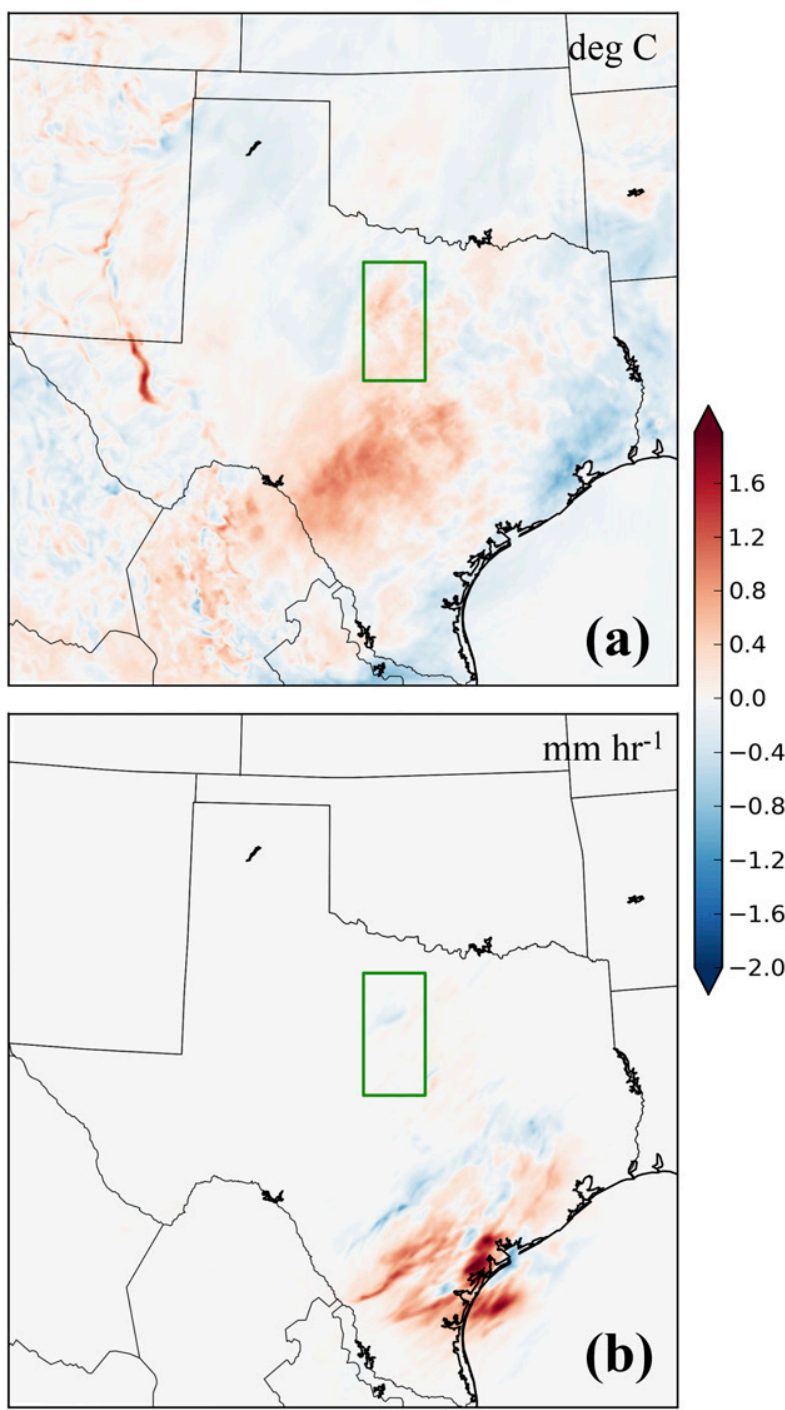

FIG. 19. (a) The 2 -m temperature $\left({ }^{\circ} \mathrm{C}\right.$, shaded) and (b) hourly rainfall $\left(\mathrm{mm} \mathrm{h}^{-1}\right.$, shaded) differences at forecast hour 14 between the convecting and nonconvecting ensemble subsets for MAY15.

ensemble is in the denominator of (1). The opposite is also true in this case; the largest positively sensitive areas to $2-\mathrm{m}$ temperature correspond to weakly positive SMDs. Less clarity is obtained by comparing the $\mathrm{SMD}_{\mathrm{TD} 2}$ and sensitivity of MDBZ to dewpoint (cf. Figs $17 \mathrm{~b}$ and 11f). Positively and negatively sensitive areas south and southwest of the response region correspond to weak positive and negative SMDs, respectively.

Closer comparison between the subset and sensitivity methods for mesoscale phenomena reveals further similarities. In instances where prior precipitation may be influencing the $\mathrm{CI}$ forecast, the objective differencing technique is valuable in assessing how ensemble sensitivity highlights the differences in cold pool formation and propagation among ensemble members. Sensitivities of MDBZ to 2-m temperature and sea level pressure at forecast hour 18 (Fig. 18, top row) in MAY15 are compared to SMDs of temperature $\left(\mathrm{SMD}_{\mathrm{T} 2}\right)$ and pressure $\left(\mathrm{SMD}_{\mathrm{SLP}}\right)$ (Fig. 18, bottom row). At forecast hour 14 , convection-producing members have a warmer air mass over central Texas than nonconvection members (Fig. 19a), associated with a displacement of antecedent precipitation east and southeastward (Fig. 19b). As this modified thermodynamic environment is advected northwestward through the low-level southeasterly flow, a positive signal in sensitivity to $2-\mathrm{m}$ temperature develops in central Texas (Fig. 18a) and is confirmed by the $\mathrm{SMD}_{\mathrm{T} 2}$ (Fig. 18c). In other words, ensemble members producing convection benefit from a southeastward displacement of the cold pool that does not adversely affect the response region prior to CI. Analyzing the SMD $_{\text {SLP }}$ within southeast Texas illustrates the hydrostatic relationship between pressure and temperature; a colder and more moist thermodynamic environment is collocated with higher pressure (Fig. 18d), indicative of the relationship of cold pool strength and pressure responses.

Moreover, a negative sensitivity to dewpoint temperature, induced by the cold pool, should be advected with the positive temperature sensitivity. As mentioned in the previous section, a signal of dewpoint sensitivity originates a few hours prior to initiation out in front of the dryline (Fig. 11f), collocated with positive temperature sensitivities in southeast Texas. A cooler and moist outflow from the antecedent convection will overrun the favorable thermodynamic environment in the response region, hindering convective development. Thus, we see that members not producing convection have a cooler and more moist environment and ESA has captured the impact that a precipitation-modified thermodynamic environment has on the initiation of convection through multiple surface-based forecast variables.

Furthermore, high visual correlations also exist between SMDs and sensitivities to 700-hPa temperatures. As was discussed previously, an area of negative sensitivity at $700 \mathrm{hPa}$ emanating from southwest Texas is present at early forecast lead times, which moves northeastward toward the response region in APR3. This feature was hypothesized to be important in reducing the strength of a capping inversion that was impeding convective development. The $\mathrm{SMD}_{\mathrm{T} 700}$ clearly highlights this feature (Fig. 20) as a location where convecting members are much cooler than nonconvecting members. Positive sensitivity downstream of the negative sensitivity region is also well correlated with positive $700-\mathrm{hPa}$ temperature differences (cf. Figs. 13 and 20), i.e., members producing convection are 

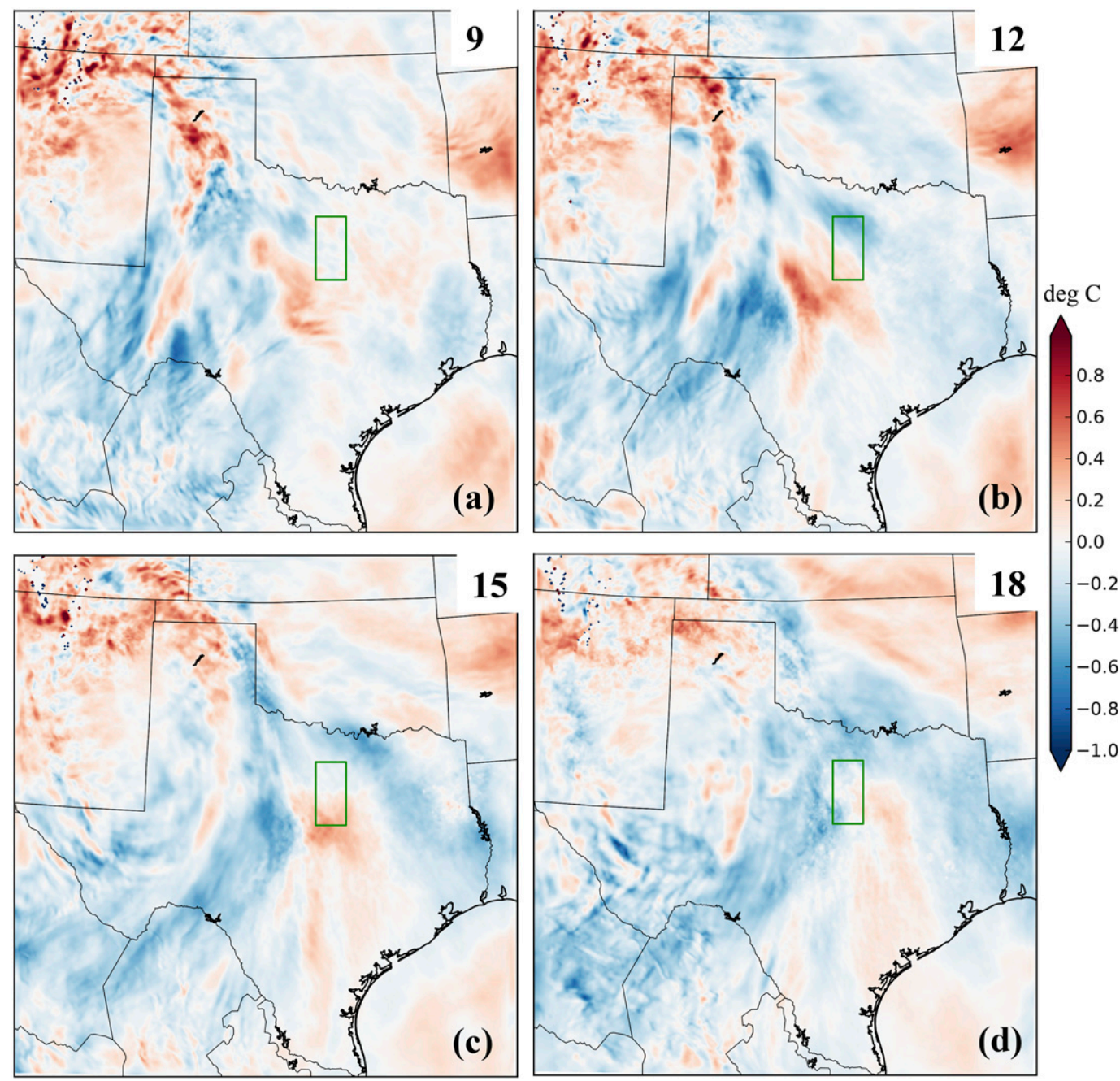

FIG. 20. Differences in 700-hPa temperature $\left({ }^{\circ} \mathrm{C}\right.$, shaded) at forecast hours (a) 9, (b) 12, (c) 15, and (d) 18 in APR3 between the convecting and nonconvecting ensemble subsets.

warmer downstream. It is also fairly clear that the sensitivity feature highlighted in MAY15 tracks with the $\mathrm{SMD}_{\mathrm{T} 700}$ (cf. Figs. 14 and 21). Members producing convection are cooler in this region, where a stronger short-wave trough may be aiding in convective development.

The correlation and collocation of sensitivity features and SMDs between members producing convection and members that do not validate the dynamic relationship ESA builds between the CI forecast and variables that may inhibit or promote convection. The underpinning feature of ESA is a simple linear regression, which even when applied to complicated non-Gaussian distributions, can capture the dynamics revealed by SMDs. In these two cases, linear regressions of bimodal distributions sufficiently identified dynamic influences on the CI forecasts. Thus, the application of ESA is useful well beyond linearly evolving and normally distributed forecast metrics.

\section{Summary and discussion}

Two ensemble forecasts of dryline convection initiation are analyzed in this study to determine if ensemble sensitivity analysis is able to identify features that may impact the initiation of storms. Forecasts are produced through a 48-h cycling WRF-EAKF modeling and data assimilation system. A simple proxy for convection initiation is chosen as the forecast metric, maximum composite reflectivity, valid in regions that exhibited convective development by some ensemble members. By choosing a time that not all ensemble members produced convection, a bimodal forecast distribution was produced, providing a stringent test for ESA in the 


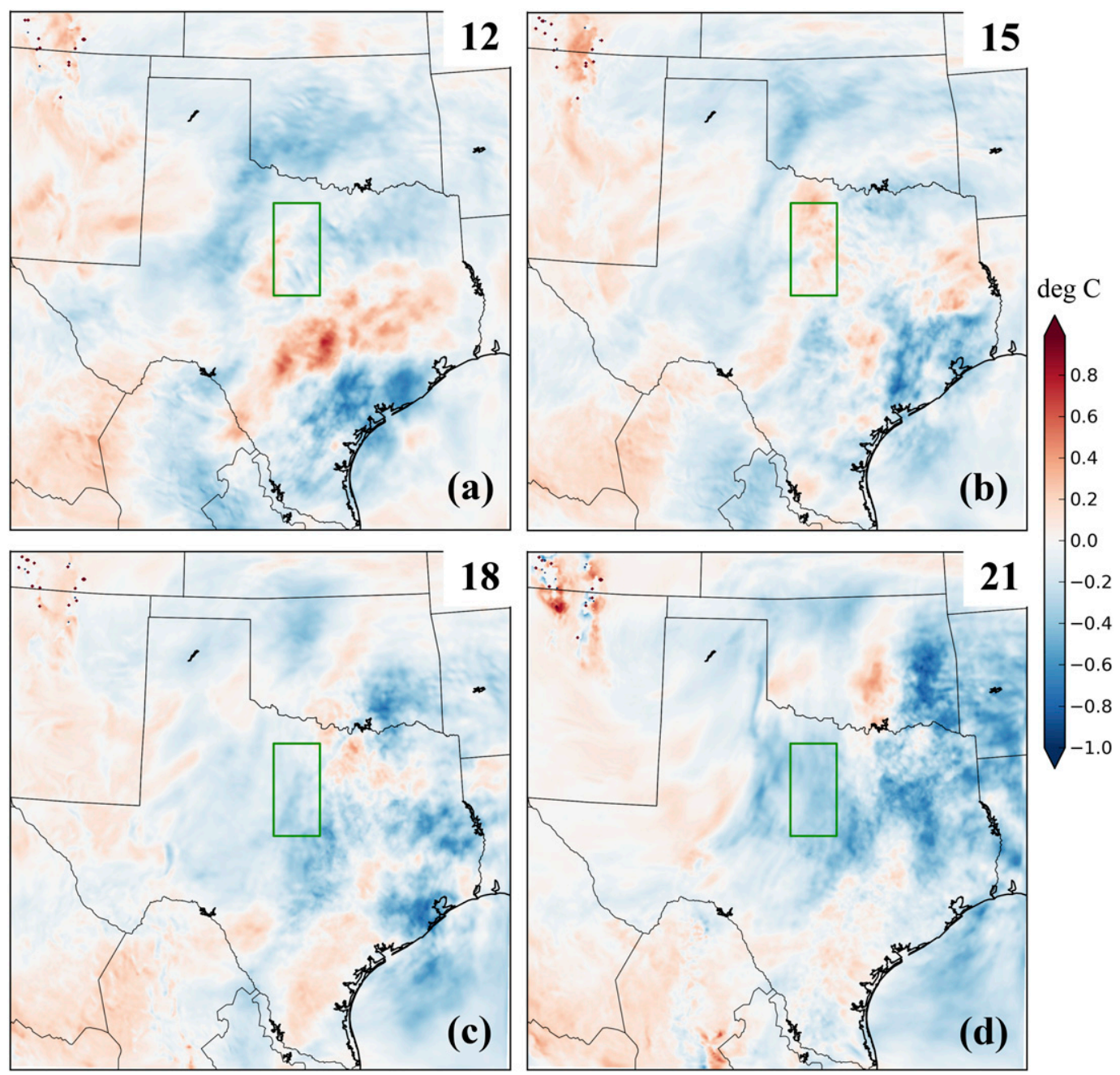

FIG. 21. As in Fig. 20, but for MAY15 at forecast hours (a) 12, (b) 15, (c) 18, and (d) 21.

presence of substantial nonlinearity and with nonnormal response function distributions. ESA was applied to the metric and regressed back to all model times so that the temporal and spatial coherency of sensitivity features could help identify the utility of ESA at various forecast lead times. Sensitivities to initial conditions at the surface and aloft identified features that are well known to influence dryline $\mathrm{CI}$ including thermodynamic properties of the upstream air mass, dryline placement, and the strength of the capping inversion. In both cases, ESA also identified the location of mesoscale features aloft (e.g., 700-hPa short-wave trough) that potentially had a direct impact on CI during the forecast period. It was also discovered that sensitivity of CI to surface fields is important at much shorter lead times than sensitivities to variables aloft, which existed through the entire forecast period. These differences are simply tied to the evolution of synoptic features versus mesoscale influences. For instance, in MAY15, precipitation ahead of the dryline modified the upstream air mass during the early afternoon hours, which moved into the response region by the time initiation was occurring. ESA was able to identify the sensitivity of CI to the thermodynamics with a few hours lead time. On the other hand, a mesoscale feature at $700 \mathrm{hPa}$ was present at early forecast times and ESA identified and tracked the feature through the entire forecast period.

Comparisons between ESA and ensemble member differences at various forecast lead times were investigated to address how ESA highlights the progression of the nonlinear forecast evolution and resulting non-Gaussian response of storm initiation. Two ensemble subsets were created that consisted of members producing convection at the response time and members that did not, with a threshold of $20 \mathrm{dBZ}$ to delineate the subsets. Model fields from the subset of nonconvectionproducing members were then subtracted from the fields 
of convection-producing members. Statistically significant positive and negative sensitivities were strongly correlated with the same sign of SMDs. In other words, positively sensitive areas where an increase in the model state variable would promote initiation were correlated to areas where convecting members had a higher mean magnitude of that state variable (positive difference). This finding was true across surface and midtropospheric variables analyzed.

While it has been shown in this study that ESA can be successfully applied to non-Gaussian forecasts of mesoscale convection initiation, limitations likely still exist with this method. Sampling error as a result of limited ensemble members, although addressed partially with statistical significance testing in this study, may inhibit the proper identification of important small-scale sensitivity features (Wile et al. 2015). It has been suggested that deficiencies in properly identifying and treating sampling error may lead to an overestimation of the sensitivity values (Hacker and Lei 2015). A more objective approach to validating the sensitivity estimations through explicit perturbation experiments may be used to account for sampling error as well as the use of inflation, localization of observations, and model error. These evaluations are beyond the scope of the current study but will be the focus of future investigations into the utility of ESA. ESA also may be utilized for forecasts of wind ramps, winter precipitation types, and storm-scale simulations of individual thunderstorms. Enhancements to the current methodology may be required to account for increasing nonlinearity as ESA is applied at smaller and smaller scales.

Extensions of ESA parallel previous studies regarding observation targeting, applying the technique on mesoscale features that may influence severe convection. What has been demonstrated in this study is that ESA is useful for bimodal forecasts of CI. It would be reasonable then to suggest that ESA-based targeting methods might be a benefit to forecasts when applied to non-Gaussian forecast responses. ESA-based targeting methods outlined by Ancell and Hakim (2007) combine information from the sensitivity fields and ensemble variance to coordinate where additional observations should be gathered to reduce uncertainty in the forecast. Investigating this targeting technique might bring value to understanding how mesoscale predictability of CI could be improved, and is a planned next step in this work.

Acknowledgments. This work was supported through the National Oceanic and Atmospheric Administration CSTAR Grant NA11NWS4680001. The authors appreciate the comments and suggestions of three anonymous reviewers.

\section{REFERENCES}

Ancell, B. C., 2013: Nonlinear characteristics of ensemble perturbation evolution and their application to forecasting highimpact events. Wea. Forecasting, 28, 1353-1365, doi:10.1175/ WAF-D-12-00090.1.

— sensitivity analysis with applications to observation targeting. Mon. Wea. Rev., 135, 4117-4134, doi:10.1175/2007MWR1904.1.

Anderson, J. L., 2001: An ensemble adjustment Kalman filter for data assimilation. Mon. Wea. Rev., 129, 2884-2903, doi:10.1175/ 1520-0493(2001)129<2884:AEAKFF >2.0.CO;2.

- 2007: An adaptive covariance inflation error correction algorithm for ensemble filters. Tellus, 59A, 210-224, doi:10.1111/j.1600-0870.2006.00216.x.

_ 2009: Spatially and temporally varying adaptive covariance inflation for ensemble filters. Tellus, 61A, 72-83, doi:10.1111/ j.1600-0870.2008.00361.x.

—, T. Hoar, K. Raeder, H. Liu, N. Collins, R. Torn, and A. Avellano, 2009: The Data Assimilation Research Testbed: A community facility. Bull. Amer. Meteor. Soc., 90, 1283-1296, doi:10.1175/2009BAMS2618.1.

Atkins, N. T., R. M. Wakimoto, and C. L. Ziegler, 1998: Observations of the finescale structure of a dryline during VORTEX 95. Mon. Wea. Rev., 126, 525-550, doi:10.1175/1520-0493(1998)126<0525: OOTFSO $>2.0 . \mathrm{CO} ; 2$.

Barker, D. M., W. Huang, Y.-R. Guo, J. Bourgeois, and Q. N. Xiao, 2004: A three-dimensional variational data assimilation system for MM5: Implementation and initial results. Mon. Wea. Rev., 132, 897-914, doi:10.1175/1520-0493(2004)132<0897: ATVDAS $>2.0 . \mathrm{CO} ; 2$.

Bednarczyk, C. N., and B. C. Ancell, 2015: Ensemble sensitivity analysis applied to a southern plains convective event. Mon. Wea. Rev., 143, 230-249, doi:10.1175/MWR-D-13-00321.1.

Bryan, G. H., 2005: Spurious convective organization in simulated squall lines owing to moist absolutely unstable layers. Mon. Wea. Rev., 133, 1978-1997, doi:10.1175/MWR2952.1.

Carlson, T., and F. Ludlam, 1968: Conditions for the occurrence of severe local storms. Tellus, 20A, 203-226, doi:10.1111/ j.2153-3490.1968.tb00364.x.

Chang, E. K. M., M. Zheng, and K. Raeder, 2013: Medium-range ensemble sensitivity analysis of two extreme Pacific extratropical cyclones. Mon. Wea. Rev., 141, 211-231, doi:10.1175/ MWR-D-11-00304.1.

Chen, F., and J. Dudhia, 2001: Coupling an advanced land surfacehydrology model with the Penn State-NCAR MM5 modeling system. Part I: Model implementation and sensitivity. Mon. Wea. Rev., 129, 569-585, doi:10.1175/1520-0493(2001)129<0569: $\mathrm{CAALSH}>2.0 . \mathrm{CO} ; 2$.

Clark, A. J., W. A. Gallus, M. Xue, and F. Kong, 2009: A comparison of precipitation forecast skill between small convection-allowing and large convection-parameterizing ensembles. Wea. Forecasting, 24, 1121-1140, doi:10.1175/ 2009WAF2222222.1.

- M. C. Coniglio, B. E. Coffer, G. Thompson, M. Xue, and F. Kong, 2015: Sensitivity of 24-h forecast dryline position and structure to boundary layer parameterizations in convectionallowing WRF Model simulations. Wea. Forecasting, 30, 613-638, doi:10.1175/WAF-D-14-00078.1.

Coffer, B. E., L. C. Maudlin, P. G. Veals, and A. J. Clark, 2013: Dryline position errors in experimental convection-allowing NSSL-WRF model forecasts and the operational NAM. Wea. Forecasting, 28, 746-761, doi:10.1175/WAF-D-12-00092.1. 
Doswell, C. A., and L. F. Bosart, 2001: Extratropical synoptic-scale processes and severe convection. Severe Convective Storms, Meteor. Monogr., No. 50, 27-70, doi:10.1175/0065-9401-28.50.27.

Dudhia, J., 1989: Numerical study of convection observed during the winter monsoon experiment using a mesoscale twodimensional model. J. Atmos. Sci., 46, 3077-3107, doi:10.1175/ 1520-0469(1989)046<3077:NSOCOD $>2.0 . C O ; 2$.

Errico, R. M., 1997: What is an adjoint model? Bull. Amer. Meteor. Soc., 78, 2577-2591, doi:10.1175/1520-0477(1997)078<2577: WIAAM $>2.0 . \mathrm{CO} ; 2$.

—_, and T. Vukićević, 1992: Sensitivity analysis using an adjoint of the PSU-NCAR mesoscale model. Mon. Wea. Rev., 120, 1644-1660, doi:10.1175/1520-0493(1992)120<1644: SAUAAO $>2.0 . \mathrm{CO} ; 2$.

_, K. D. Raeder, and L. Fillion, 2003: Examination of the sensitivity of forecast precipitation rates to possible perturbations of initial conditions. Tellus, 55A, 88-105, doi:10.1034/ j.1600-0870.2003.201394.x.

Evensen, G., 1994: Sequential data assimilation with a nonlinear quasi-geostrophic model using Monte Carlo methods to forecast error statistics. J. Geophys. Res., 99, 10143-10162, doi:10.1029/94JC00572.

Garcies, L., and V. Homar, 2009: Ensemble sensitivities of the real atmosphere: Application to Mediterranean intense cyclones. Tellus, 61A, 394-406, doi:10.1111/j.1600-0870.2009.00392.x.

_ , and — 2010: An optimized ensemble sensitivity climatology of Mediterranean intense cyclones. Nat. Hazards Earth Syst. Sci., 10, 2441-2450, doi:10.5194/nhess-10-2441-2010.

Gaspari, G., and S. E. Cohn, 1999: Construction of correlation functions in two and three dimensions. Quart. J. Roy. Meteor. Soc., 125, 723-757, doi:10.1002/qj.49712555417.

Hacker, J., and L. Lei, 2015: Multivariate ensemble sensitivity with localization. Mon. Wea. Rev., 143, 2013-2027, doi:10.1175/ MWR-D-14-00309.1.

Hakim, G. J., and R. D. Torn, 2008: Ensemble synoptic analysis. Synoptic-Dynamic Meteorology and Weather Analysis and Forecasting: A Tribute to Fred Sanders, Meteor. Monogr., No. 55, Amer. Meteor. Soc., 147-162, doi:10.1175/ 0065-9401-33.55.147.

Hamill, T., and C. Snyder, 2002: Using improved background-error covariances from an ensemble Kalman filter for adaptive observations. Mon. Wea. Rev., 130, 1552-1572, doi:10.1175/ 1520-0493(2002)130<1552:UIBECF $>2.0 . C O ; 2$.

— J. S. Whitaker, and C. Snyder, 2001: Distance-dependent filtering of background error covariance estimates in an ensemble Kalman filter. Mon. Wea. Rev., 129, 2776-2790, doi:10.1175/ 1520-0493(2001)129<2776:DDFOBE > 2.0.CO;2.

Holt, T. R., D. Niyogi, F. Chen, K. Manning, M. A. LeMone, and A. Qureshi, 2006: Effect of land-atmosphere interactions on the IHOP 24-25 May 2002 convection case. Mon. Wea. Rev., 134, 113-133, doi:10.1175/MWR3057.1.

Hong, S., Y. Noh, and J. Dudhia, 2006: A new vertical diffusion package with an explicit treatment of entrainment processes. Mon. Wea. Rev., 134, 2318-2342, doi:10.1175/MWR3199.1.

Houtekamer, P., and H. Mitchell, 1998: Data assimilation using an ensemble Kalman filter technique. Mon. Wea. Rev., 126, 796-811, doi:10.1175/1520-0493(1998)126<0796:DAUAEK >2.0.CO;2.

Ito, K., and C.-C. Wu, 2013: Typhoon-position-oriented sensitivity analysis. Part I: Theory and verification. J. Atmos. Sci., 70, 2525-2546, doi:10.1175/JAS-D-12-0301.1.

Kain, J., 2004: The Kain-Fritsch convective parameterization: An update. J. Appl. Meteor., 43, 170-181, doi:10.1175/1520-0450(2004)043<0170: TKCPAU $>2.0 . \mathrm{CO} ; 2$.
- and Coauthors, 2013: A feasibility study for probabilistic convection initiation forecasts based on explicit numerical guidance. Bull. Amer. Meteor. Soc., 94, 1213-1225, doi:10.1175/ BAMS-D-11-00264.1.

Kalnay, E., Y. Ota, T. Miyoshi, and J. Liu, 2012: A simpler formulation of forecast sensitivity to observations: Application to ensemble Kalman filters. Tellus, 64A, 1-9, doi:10.3402/ tellusa.v64i0.18462.

Kang, W., and L. Xu, 2012: Optimal placement of mobile sensors for data assimilations. Tellus, 64A, 1-12, doi:10.3402/ tellusa.v64i0.17133.

LeDimet, F., and O. Talagrand, 1986: Variational algorithms for analysis and assimilation of meteorological observations: Theoretical aspects. Tellus, 38A, 97-110, doi:10.1111/ j.1600-0870.1986.tb00459.x.

Liu, J., and E. Kalnay, 2008: Estimating observation impact without adjoint model in an ensemble Kalman filter. Quart. J. Roy. Meteor. Soc., 134, 1327-1335, doi:10.1002/qj.280.

Martin, W., and M. Xue, 2006: Sensitivity analysis of convection of the 24 May 2002 IHOP case using very large ensembles. Mon. Wea. Rev., 134, 192-207, doi:10.1175/MWR3061.1.

McMurdie, L. A., and B. Ancell, 2014: Predictability characteristics of land-falling cyclones along the North American west coast. Mon. Wea. Rev., 142, 301-319, doi:10.1175/ MWR-D-13-00141.1.

Melhauser, C., and F. Zhang, 2012: Practical and intrinsic predictability of severe and convective weather at the mesoscales. J. Atmos. Sci., 69, 3350-3371, doi:10.1175/JAS-D-11-0315.1.

Mlawer, E. J., S. J. Taubman, P. D. Brown, M. J. Iacono, and S. A. Clough, 1997: Radiative transfer for inhomogeneous atmospheres: RRTM, a validated correlated-k model for the longwave. J. Geophys. Res., 102, 16 663-16 682, doi:10.1029/ 97JD00237.

Qin, X., and M. Mu, 2011: A study on the reduction of forecast error variance by three adaptive observation approaches for tropical cyclone prediction. Mon. Wea. Rev., 139, 2218-2232, doi:10.1175/2010MWR3327.1.

Rabier, F., E. Klinker, P. Courtier, and A. Hollingsworth, 1996: Sensitivity of forecast errors to initial conditions. Quart. J. Roy. Meteor. Soc., 122, 121-150, doi:10.1002/ qj.49712252906.

Schaefer, J. T., 1986: The dryline. Mesoscale Meteorology and Forecasting, P. S. Ray, Ed., Amer. Meteor. Soc., 549-572.

Schumacher, R. S., 2015: Resolution dependence of initiation and upscale growth of deep convection in convection-allowing forecasts of the 31 May-1 June 2013 supercell and MCS. Mon. Wea. Rev., 143, 4331-4354, doi:10.1175/MWR-D-15-0179.1.

Schwartz, C. S., G. S. Romine, K. R. Smith, and M. L. Weisman, 2014: Characterizing and optimizing precipitation forecasts from a convection-permitting ensemble initialized by a mesoscale ensemble Kalman filter. Wea. Forecasting, 29, 12951318, doi:10.1175/WAF-D-13-00145.1.

Skamarock, W. C., and Coauthors, 2008: A description of the Advanced Research WRF version 3. NCAR Tech. Note NCAR/TN-475+STR, 113 pp., doi:10.5065/D68S4MVH.

Thompson, G., R. M. Rasmussen, and K. Manning, 2004: Explicit forecasts of winter precipitation using an improved bulk microphysics scheme. Part I: Description and sensitivity analysis. Mon. Wea. Rev., 132, 519-543, doi:10.1175/1520-0493(2004)132<0519: EFOWPU $>2.0 . \mathrm{CO} ; 2$.

Torn, R. D., 2010: Ensemble-based sensitivity analysis applied to African easterly waves. Wea. Forecasting, 25, 61-78, doi:10.1175/2009WAF2222255.1. 
2014: The impact of targeted dropwindsonde observations on tropical cyclone intensity forecasts of four weak systems during PREDICT. Mon. Wea. Rev., 142, 2860-2878, doi:10.1175/ MWR-D-13-00284.1.

— , and G. J. Hakim, 2008: Ensemble-based sensitivity analysis. Mon. Wea. Rev., 136, 663-677, doi:10.1175/2007MWR2132.1. and - 2009: Initial condition sensitivity of western Pacific extratropical transitions determined using ensemble-based sensitivity analysis. Mon. Wea. Rev., 137, 3388-3406, doi:10.1175/ 2009MWR2879.1.

— , and D. Cook, 2013: The role of vortex and environment errors in genesis forecasts of Hurricanes Danielle and Karl (2010). Mon. Wea. Rev., 141, 232-251, doi:10.1175/MWR-D-12-00086.1.

— convection forecasts to upstream potential vorticity anomalies during two strongly forced cases during MPEX. Mon. Wea. Rev., 143, 4064-4087, doi:10.1175/MWR-D-15-0085.1.

— G. J. Hakim, and C. Snyder, 2006: Boundary conditions for limited-area ensemble Kalman filters. Mon. Wea. Rev., 134, 2490-2502, doi:10.1175/MWR3187.1.

Weisman, M. L., and Coauthors, 2015: The Mesoscale Predictability Experiment (MPEX). Bull. Amer. Meteor. Soc., 96, 2127-2149, doi:10.1175/BAMS-D-13-00281.1.

Weiss, C., and H. Bluestein, 2002: Airborne pseudo-dual Doppler analysis of a dryline-outflow boundary intersection. Mon. Wea. Rev., 130, 1207-1226, doi:10.1175/1520-0493(2002)130<1207: APDDAO $>2.0 . \mathrm{CO} ; 2$.

— - _ and A. Pazmany, 2006: Finescale radar observations of the 22 May 2002 dryline during the International $\mathrm{H}_{2} \mathrm{O}$ Project (IHOP). Mon. Wea. Rev., 134, 273-293, doi:10.1175/MWR3068.1.

Wile, S. M., J. P. Hacker, and K. H. Chilcoat, 2015: The potential utility of high-resolution ensemble sensitivity analysis for observation placement during weak flow in complex terrain. Wea. Forecasting, 30, 1521-1536, doi:10.1175/WAF-D-14-00066.1.

Wilks, D. S., 2011: Statistical Methods in the Atmospheric Sciences. Academic Press, 676 pp.

Xie, B., F. Zhang, Q. Zhang, J. Poterjoy, and Y. Weng, 2013: Observing strategy and observation targeting for tropical cyclones using ensemble-based sensitivity analysis and data assimilation. Mon. Wea. Rev., 141, 1437-1453, doi:10.1175/ MWR-D-12-00188.1.

Zack, J., E. Natenberg, S. Young, G. V. Knowe, K. Waight, J. Manobianco, and C. Kamath, 2010a: Application of ensemble sensitivity analysis to observation targeting for short-term wind speed forecasting in the Washington-Oregon region. Lawrence Livermore National Laboratory Tech. Rep. LLNL-TR-458086, Livermore, CA, 65 pp.

$-,-1,-$, G. Van Knowe, K. Waight, J. Manobainco, and C. Kamath, 2010b: Application of ensemble sensitivity analysis to observation targeting for short-term wind speed forecasting in the Tehachapi region winter season. Lawrence Livermore National Laboratory Tech. Rep. LLNL-TR460956, Livermore, CA, $57 \mathrm{pp}$.

,,,--- J. Manobianco, and C. Kamath, 2010c: Application of ensemble sensitivity analysis to observation targeting for short-term wind speed forecasting. Lawrence Livermore National Laboratory Tech. Rep. LLNL-TR-424442, Livermore, CA, 32 pp.

, E. J. Natenberg, G. V. Knowe, K. Waight, J. Manobianco, D. Hanley, and C. Kamath, 2011a: Observing system simulation experiments (OSSEs) for the Mid-Columbia basin. Lawrence Livermore National Laboratory Tech. Rep. LLNLTR-499162, Livermore, CA, 17 pp.

—, E. Natenberg, G. Knowe, J. Manobianco, K. Waight, D. Hanley, and C. Kamath, 2011b: Use of data denial experiments to evaluate ESA forecast sensitivity patterns. Lawrence Livermore National Laboratory Tech. Rep. LLNL-TR-499166, Livermore, CA, 33 pp.

Zhang, F., C. Snyder, and R. Rotunno, 2003: Effects of moist convection on mesoscale predictability. J. Atmos. Sci., 60, 1173-1185, doi:10.1175/1520-0469(2003)060<1173 $\mathrm{EOMCOM}>2.0 . \mathrm{CO} ; 2$

Ziegler, C. L., and E. N. Rasmussen, 1998: The initiation of moist convection at the dryline: Forecasting issues from a case study perspective. Wea. Forecasting, 13, 1106-1131, doi:10.1175/ 1520-0434(1998)013<1106:TIOMCA>2.0.CO;2. 


\title{
CORRIGENDUM
}

\author{
Aaron J. Hill, ${ }^{a}$ Christopher C. Weiss, ${ }^{a}$ And Brian C. AnCEll ${ }^{a}$ \\ ${ }^{a}$ Department of Geosciences, Texas Tech University, Lubbock, Texas
}

(Manuscript received 12 May 2020, in final form 16 February 2021)

In Hill et al. (2016), there were errors in the reporting of covariance localization half-widths, both in the horizontal and vertical. The horizontal half-widths were reported as 600 and $300 \mathrm{~km}$ and the vertical half-widths were reported as 0.075 and $0.025 \mathrm{~km}$ for the outermost and inner domains, respectively. These half-width values of the Gaspari-Cohn localization function (Gaspari and Cohn 1999) come from a Data Assimilation Research Testbed (Anderson et al. 2009) namelist, which was incorrectly interpreted. The horizontal half-widths should have been calculated as the product of the namelist cutoff value (e.g., 0.05) and radius of Earth in kilometers. The vertical localization half-widths should have been calculated as the product of the cutoff value and normalization distance, which in this instance was $10000 \mathrm{~m}$. Therefore, the horizontal localization half-widths should be 950 and $320 \mathrm{~km}$, and the vertical half-widths 1.5 and $0.5 \mathrm{~km}$, for the outer and nested domains, respectively. These reporting errors were only typographical in nature and in no way impacted the results therein.

\section{REFERENCES}

Anderson, J. L., T. Hoar, K. Raeder, H. Liu, N. Collins, R. Torn, and A. Avellano, 2009: The Data Assimilation Research Testbed: A community facility. Bull. Amer. Meteor. Soc., 90, 1283-1296, https:// doi.org/10.1175/2009BAMS2618.1.

Gaspari, G., and S. E. Cohn, 1999: Construction of correlation functions in two and three dimensions. Quart. J. Roy. Meteor. Soc., 125, 723-757, https://doi.org/10.1002/qj.49712555417.

Hill, A. J., C. C. Weiss, and B. C. Ancell, 2016: Ensemble sensitivity analysis for mesoscale forecasts of dryline convection initiation. Mon. Wea. Rev., 144, 4161-4182, https://doi.org/10.1175/MWR-D-15-0338.1.

Hill's current affiliation: Department of Atmospheric Science, Colorado State University, Fort Collins, Colorado.

Corresponding author: Aaron J. Hill, aaron.hill@colostate.edu 